\title{
SOLIDIFICATION/STABILIZATION OF TOXIC METALS IN CALCIUM ALUMINATE CEMENT MATRICES
}

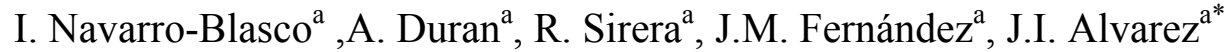 \\ ${ }^{a}$ Inorganic Materials \& Environment (MIMED), School of Sciences, University of \\ Navarra. Irunlarrea, 1. 31008 Pamplona, Spain \\ * Corresponding author: \\ Dr. José I. Alvarez \\ University of Navarra \\ Irunlarrea, 1. 31008 Pamplona, Spain \\ Phone: +34948425600 \\ Fax: +34948425740 \\ E-mail: jalvarez@unav.es, mimed@unav.es
}




\section{ABSTRACT}

The ability of calcium aluminate cement $(\mathrm{CAC})$ to encapsulate toxic metals $(\mathrm{Pb}, \mathrm{Zn}$ and $\mathrm{Cu}$ ) was assessed under two curing conditions. Changes in the consistency and in the setting time were found upon the addition of the nitrates of the target metals. Both $\mathrm{Pb}$ and $\mathrm{Cu}$ caused a delay in $\mathrm{CAC}$ hydration, while $\mathrm{Zn}$ accelerated the stiffening of the mortar. Compressive strengths of the metal-doped mortars, when initially cured at $60^{\circ} \mathrm{C} / 100 \% \mathrm{RH}$, were comparable with that of the free-metal mortar. Three different pore size distribution patterns were identified and related to the compounds identified by XRD and SEM. Sorbent capacities of CAC for the toxic metals were excellent: a total uptake was achieved for up to $3 \mathrm{wt} \%$ loading of the three metals. In this way, CAC mortars were perfectly able to encapsulate the toxic metals, allowing the use of CAC for waste management as proved by the leaching tests.

Keywords: metal; cement; sorption; leaching; strength 


\section{INTRODUCTION}

Heavy metal bearing waste normally needs solidification/stabilization $(\mathrm{S} / \mathrm{S})$ processes to reduce contaminant leaching prior to landfill disposal. Cement is the most adaptable binder currently available for this immobilization. A growing number of papers have dealt with this subject, mainly using ordinary Portland cement (OPC), some of its phases or OPC modified by calcium aluminate, calcium sulphate, and/or admixtures [17], occasionally forming new phases with the metallic cations. In addition, G. Qian and co-workers have extensively studied the $\mathrm{S} / \mathrm{S}$ processes of toxic metals in fly ashcalcium sulfoaluminate cement, Friedel's salt or fly ashes [8-10].

CAC is an alternative construction material to OPC. This type of cement is especially employed in the production of fire-resistant materials and in cases in which concreting in temperatures below zero or a fast increase in strength is required [11]. Different calcium aluminate compounds, such as $\mathrm{CA}, \mathrm{CA}_{2}$ and $\mathrm{C}_{12} \mathrm{~A}_{7}$, exist, the reactivity increasing when $\mathrm{CaO}$ content rises. CAC reaction with water usually leads to the formation of metastable hexagonal phases, $\mathrm{CAH}_{10}$ and $\mathrm{C}_{2} \mathrm{AH}_{8}$ and amorphous aluminium hydroxide, which is followed by the formation of the stable cubic phases $\mathrm{C}_{3} \mathrm{AH}_{6}$ and $\mathrm{AH}_{3}$ at higher temperature and in the presence of humidity. This process is associated with an increase in porosity -owing to a contraction in the volume of solidsand a subsequent decrease in strength [12-13].

Recently CACs have been reported to show potential advantages when used to encapsulate certain toxic and radioactive wastes [14], owing to their high early strength, chemical attack resistance and abrasion endurance [15]. Interaction between CACs and alkaline and alkaline-earth metal chlorides has been reported focusing on the hydration chemistry and on the setting behavior [16-18]. Results were recognized to be unclear and sometimes opposite to those obtained with OPC. The effect of counter-ions 
(sulphates, chlorides or nitrates) cannot be disregarded [19]. Only a few studies dealing with the effect of some transition metal chlorides and sulphates on CAC have so far been reported $[15,20]$. However, the performance of CAC when toxic metal nitrates are added has scarcely been researched. In addition, the effectiveness of CAC in the stabilization of hazardous waste containing soluble toxic metals remains to be ascertained. Both issues are addressed in the current paper. The effect of $\mathrm{Pb}, \mathrm{Zn}$ and $\mathrm{Cu}$ nitrates on the fresh and hardened state properties of the CAC matrices is discussed. To this end, two sets of CAC samples, cured under two different environmental conditions -the second one selected in order to favor the formation of stable phases- were assayed and later studied on different days. The phase assemblage of the modified CAC mortars was also analyzed by XRD and related to the microstructure of the mortars and their compressive strengths. Both adsorption isotherms of the metals on CAC and leaching tests were carried out in order to ascertain the effectiveness of these CAC matrices in $\mathrm{S} / \mathrm{S}$ processes of toxic metals.

\section{MATERIAL AND METHODS}

\subsection{Materials}

A CAC (Ciments Molins) was used as the binding phase. Its XRD analysis showed CA as the main mineralogical phase (ICDD 01-070-0134), together with amounts of $\mathrm{C}_{12} \mathrm{~A}_{7}$, mayenite, (ICDD 09-0413), $\mathrm{C}_{5} \mathrm{~A}_{3}$ (ICDD 01-1057), $\mathrm{C}_{3} \mathrm{~A}$ (ICDD 01-1060) and $\mathrm{C}_{4} \mathrm{AF}$ (ICDD 30-0226). The average wt.\% composition was: $\mathrm{Al}_{2} \mathrm{O}_{3} 41 \%, \mathrm{CaO} 38 \%, \mathrm{Fe}_{2} \mathrm{O}_{3}$ $17 \%, \mathrm{SiO}_{2} 3 \%, \mathrm{SO}_{3} 0.1 \%, \mathrm{Na}_{2} \mathrm{O}+\mathrm{K}_{2} \mathrm{O} 0.1 \%$. The aggregate was a standard siliceous sand (99 wt.\% of $\mathrm{SiO}_{2}$ ), evenly graded, with particle diameter ranging from 0.05 to 2 $\mathrm{mm}$. 
Soluble $\mathrm{Pb}\left(\mathrm{NO}_{3}\right)_{2}, \mathrm{Zn}\left(\mathrm{NO}_{3}\right)_{2}$, and $\mathrm{Cu}\left(\mathrm{NO}_{3}\right)_{2}$ (Merck) were chosen for the metal load (1 wt.\% metal/cement).

\subsection{Sample preparation}

Cement and aggregate (1:3 ratio by weight) were blended for $5 \mathrm{~min}$ in a mixer. Afterwards, the mixing water ( 0.4 water/cement ratio) was added and mixed for $90 \mathrm{~s}$. When required, one of the selected metal salts was dissolved in the mixing water. Four different batches of samples were prepared: a plain CAC mortar (control group) and three batches of samples modified upon the addition of, respectively, $\mathrm{Pb}, \mathrm{Zn}$ and $\mathrm{Cu}$.

According to the procedures described below, fresh state properties were evaluated. For the assessment of the hardened state characteristics, cylindrical $(5 \mathrm{~cm}$ height and $3.5 \mathrm{~cm}$ diameter) PVC molds were filled with the fresh mixture. Specimens were cured until the test day. For each batch of samples, two different curing conditions were chosen:

- Curing 1: $20^{\circ} \mathrm{C}$ and 95\% RH [21] over the whole curing period.

- Curing 2: $60^{\circ} \mathrm{C}$ and $100 \%$ RH [22] for 24 hours. Once this period was completed, temperature and $\mathrm{RH}$ were shifted towards $20^{\circ} \mathrm{C}$ and $95 \% \mathrm{RH}$.

Under condition 1, CAC samples were expected to develop metastable hydrated phases. However, condition 2 was performed to enhance the formation of stable hydrates.

For each period of curing $(1,3,7,14$ and 28 days), three specimens of each one of the different mortar compositions were prepared to ensure the statistical significance of data. The results reported were the average values. 


\subsection{Experimental tests}

In fresh and hardened state, mortars properties were calculated according to the standardized procedures reported elsewhere [5,23]: consistency (measuring the slump through the mini-spread flow test), water retention capacity, open time and compressive strength.

In order to arrest the ongoing hydration, samples were subjected to a freeze-drying procedure, intended to remove all water. Afterwards, pore size distributions (PSD) by mercury intrusion porosimetry (MIP) and mineralogical composition (X-ray diffraction, XRD) were determined [5]. Based on the diffraction peaks intensities, the relative amount of the different crystalline phases was established in a semi-quantitative approach [24] that took into account the difficulties related to the proper quantitative estimation of the CAC systems.

The textural characteristics of the samples and elemental mapping were performed, after coating with a gold film, by means of scanning electron microscopy (SEM), in a Hitachi S-4800 microscope, coupled to a EDS detector.

Sorption studies were carried out by batch process. Aqueous solutions $(50 \mathrm{mg} / \mathrm{L})$ of $\mathrm{CAC}$ were loaded with sorbate (metal nitrates, ranging from 0 to $10 \mathrm{wt} . \%$ with respect to the sorbent). The mixtures were allowed to reach equilibrium under stirring for 60 min. The solid compounds were separated by centrifuging and the supernatant was filtered through a $0.45 \mu \mathrm{m}$ filter. Solid phase was assessed by XRD and, when deemed necessary, by Fourier transform infrared-attenuated total reflectance (FTIR-ATR) spectroscopy, while residual metal concentration of this clear solution was determined by atomic absorption spectrometry (AAS) (Perkin-Elmer AAnalyst-800) [23]. Steadystate data were fitted to the Langmuir and Freundlich models [25]. 
Monolithic test pieces were subjected to leaching tests by a semi-dynamic Tank-Test [26]. Eluates were collected at eight times $(0.25,1,2.25,4,9,16,36$ and 64 days) and the residual metal concentrations were determined by AAS. Cumulative leachings were calculated as described elsewhere [5] and the leaching mechanism was determined from the slope of the linear regression analysis as detailed in the norm [26].

\section{RESULTS AND DISCUSSION}

\subsection{Effects of metal incorporation on CAC mortar performance}

The presence of $\mathrm{Pb}\left(\mathrm{NO}_{3}\right)_{2}$ and $\mathrm{Cu}\left(\mathrm{NO}_{3}\right)_{2}$, under curing condition 1, caused a marked fluidity increase (rise in the slump values; Table 1) with respect to the reference mortar (by $30 \%$ and $63 \%$, respectively). The workable life increased by $23 \%$ for $\mathrm{Pb}$-doped samples and by $30 \%$ for $\mathrm{Cu}$-doped samples. In contrast, the addition of $\mathrm{Zn}\left(\mathrm{NO}_{3}\right)_{2}$ dramatically changed the workable life, which was reduced by $91 \%$.

Under curing condition 1, the addition of the three toxic metals was detrimental to the strength of the mortars (Fig. 1a). In 28-days aged Pb-bearing mortars the strength was reduced by as much as $75 \%$. The presence of $\mathrm{Cu}$ provoked a dramatic strength reduction: in most cases, the compressive strength results were almost negligible. This fact can be related to a strongly delayed hydration of the cement particles: since samples were not hydrated, they broke easily.

Curing condition 2 clearly favored the compressive strength of the $\mathrm{Pb}$ and $\mathrm{Cu}$-bearing CAC mortars (Fig. 1b, Fig. 2). From day-7 onwards, the measured compressive strength of the $\mathrm{Pb}$-doped mortars was even larger than that of the control group. For $\mathrm{Cu}$-bearing mortars, the change in curing conditions clearly improved the strength (Fig. 2c). As for 
Zn-doped cements, medium-term cured samples (14 and 28 days) showed similar compressive strengths to those of the control group.

As a general trend, the metal-doped CAC samples cured under condition 2 showed higher compressive strengths than those reported in the literature for metal-doped OPC specimens [27-28], that is of the utmost importance for using CAC in the $\mathrm{S} / \mathrm{S}$ processes of toxic metals as an alternative to OPC. In general, but in the case of $\mathrm{Cu}$ loading under curing condition 1 , the majority of the mechanical resistances of the 28 -day-aged metaldoped CAC mortars were satisfactory, allowing the safe handling of these materials and their deposition in industrial landfills. Values fulfil the requirements of strength for monolithic wastes to be accepted in landfills for hazardous wastes (1 MPa after 28 curing days) [29] and, in general, the more demanding requirements for using the matrix in concrete masonry units (13MPa) [30].

\subsection{Phase assemblage and microstructural characterization of the metal-doped}

\section{CAC samples}

XRD was used to study the evolution of the different cementitious phases after each curing period (Fig. 3) and PSD was related to this phase assemblage. As reported by Gosselin et al. [24], the phase quantification by the Rietveld method cannot be easily used for CACs. Therefore, owing to the complexity of the CAC system, plotted values are estimations based on peak intensity heights (related to the area under the peak). Specifically, with respect to $\mathrm{AH}_{3}$, the estimation was made based on its most intense diffraction peak at $18.33^{\circ} 2 \theta$ (ICDD 01-076-1782), which in the assayed sample corresponds to gibbsite. 


\subsubsection{Control group}

Plain CAC specimens (curing 1) showed, as main components, metastable hydrated phases $\left(\mathrm{CAH}_{10}\right.$, Fig. 3), which yielded PSD curves in which most of the pores appeared below $0.5 \mu \mathrm{m}$ of diameter (Fig. 4). Also there is a large population of pores $<0.10 \mu \mathrm{m}$. The fine, reduced porosity of these samples accounted for their highest mechanical strengths.

These control samples under curing condition 2 showed stable hydrated phases $\mathrm{C}_{3} \mathrm{AH}_{6}$ and $\mathrm{AH}_{3}$ (gibbsite) as significantly present compounds (Fig. 3). Owing to the high density of these hydrates, the porosity of these specimens increased, thus explaining the strength reduction observed (Fig. 1) [24]: the average pore diameter was between 1-1.5 $\mu \mathrm{m}$ and the population of pores $<0.5 \mu \mathrm{m}$ of diameter contributed to a lesser extent to the total porosity (Fig. 4, condition 2). SEM examination of these very same samples confirmed these results showing cubic-shaped crystals mixed with some trapezohedral and rhombo-trapezohedral ones, all of which were of $\mathrm{C}_{3} \mathrm{AH}_{6}$ (Fig. 5a). $\mathrm{AH}_{3}$ appeared in the micrograph as needles while some hexagonal prisms could be attributable to the remaining metastable hydrates [31] (Fig. 5b).

\subsubsection{Pb-doped samples}

The incorporation of $\mathrm{Pb}$ in $\mathrm{CAC}$ samples hampered the hydration process (condition 1): anhydrous compounds prevailed over the other aluminate phases (Fig. 3). A sharp, unimodal PSD was found for Pb-doped samples (Fig. 6), with an average pore size diameter around $2 \mu \mathrm{m}$. Porosity below this pore size value was almost negligible. This PSD pattern arose as a result of the prevailing presence of anhydrous compounds, as 
confirmed by SEM (Fig. 7a), in which abundant loosely-bound unreacted cement particles and a low degree of mortar compactness can be seen. The PSD of these samples after a few curing days can be attributed to the interparticle space between anhydrous calcium aluminate grains.

Further delayed hydration in samples cured beyond 7 days resulted in: (i) the filling of the interparticle space by the hydration products; and (ii) the increase of the finest pores (diameter $<0.5 \mu \mathrm{m}$ ). The latter can be associated with the subsequent appearance of metastable hydrates, as confirmed by SEM: a significant part of these hydrates appeared in jellified ill-defined structure, which hindered their proper identification by XRD (Fig. 7b). After 28 curing days an increase in needles and hexagonally-shaped crystals of $\mathrm{CAH}_{10}$ was observed (Fig. 7c) [32].

The EDS'chemical mapping indicated that $\mathrm{Pb}$ was specially attached to calcium and aluminium compounds rather than to siliceous components (Fig. 8).

In samples aged under condition 2, the presence of $\mathrm{Pb}$ did not hinder the formation mainly of stable compounds $\left(\mathrm{C}_{3} \mathrm{AH}_{6}\right.$ and $\left.\mathrm{AH}_{3}\right)$, which systematically appeared from day-1 onwards (Fig. 3). These compounds precisely determined the PSD: similarly to the control group, reduced porosity below $0.5 \mu \mathrm{m}$ and main pore diameter around $1 \mu \mathrm{m}$ (Fig. 6). SEM examination showed a fibrous matrix owing to the presence of $\mathrm{AH}_{3}$ needles together with some cubic $\mathrm{C}_{3} \mathrm{AH}_{6}$ crystals (Fig. 7d).

Traces of two new $\mathrm{Pb}$-bearing phases were found by $\mathrm{XRD}$ : an aluminosilicate, wickenburgite $\left(\mathrm{CaPb}_{3} \mathrm{Al}_{2} \mathrm{Si}_{10} \mathrm{O}_{24}(\mathrm{OH})_{6}\right.$, ICDD 21-0148, peaks: 8.8, 27.4 20), and leadhillite $\left(\mathrm{Pb}_{4} \mathrm{SO}_{4}\left(\mathrm{CO}_{3}\right)_{2}(\mathrm{OH})_{2}\right.$, ICDD 01-085-1422, peaks: 24.1, 34.3 20$)$. Leadhillite had been reported for Pb-doped OPC samples [33]. 


\subsubsection{Zn-doped samples}

Metastable $\mathrm{C}_{2} \mathrm{AH}_{8}$ was identified in Zn-CAC mortars (curing 1) (Fig. 3). PSD depicts the characteristics of the simultaneous presence of anhydrous compounds (main pore diameter $\geq 2 \mu \mathrm{m}$ ) and metastable hydrates (significant pore population $<0.5 \mu \mathrm{m}$ ) (Fig. 9). SEM micrographs showed a gel-like structure of metastable hydrates, with reduced porosity (Fig. 10a). Areas of thin spread out gel-like layers together with some anhydrous cement particles could also be identified (Fig. 10b). These results agree well with previous data on the relatively high compressive strengths of these $\mathrm{Zn}$-CAC samples (Fig. 1a).

The EDS elemental mapping showed that Zn did not show any preferential fixation site. Spots of $\mathrm{Zn}$ appeared over the matrix both in calcium aluminate and in siliceous compounds (Fig. 11).

By XRD (Fig. 3), Zn-doped samples (curing 2) showed, alongside some phases remaining unhydrated, stable hydrated compounds $\left(\mathrm{C}_{3} \mathrm{AH}_{6}\right.$ and $\left.\mathrm{AH}_{3}\right)$, whose amount increased over the time (from 14 curing days onwards). Fig. 9 depicts a combined PSD pattern, with a split in the main peak above and below $1 \mu \mathrm{m}$ and slightly increased porosity below $0.5 \mu \mathrm{m}$. No evidence of new Zn-bearing compounds could be identified by XRD. SEM analysis showed some cubic and trapezohedrally shaped crystals of $\mathrm{C}_{3} \mathrm{AH}_{6}$ (Fig. 10c) and gibbsite needle-shaped crystals (Fig. 10d), confirming the XRD results.

\subsubsection{Cu-doped samples}


The presence of $\mathrm{Cu}$ (condition 1) almost completely protected the anhydrous aluminate phases from hydration. XRD measurements of $\mathrm{Cu}$-doped samples did not reveal the presence of hydrated compounds except a tiny amount of $\mathrm{CAH}_{10}$ (Fig. 3). Accordingly, the PSD was similar to $\mathrm{Pb}$-samples, with a unimodal distribution (main pore diameter ca. $2 \mu \mathrm{m}$ ) and only a few pores with diameters $<0.5 \mu \mathrm{m}$ (Fig. 12). This fact accounted for the low -almost negligible- compressive strengths of these samples (Fig. 1a and 2c).

SEM examination (Fig. 13a) showed an ill-defined microstructure, with an outstanding number of anhydrous cement particles poorly bonded that led to a large degree of porosity. Some newly formed flaky plate-like crystals of metastable hydrates $\left(\mathrm{CAH}_{10}\right)$, were found in rosette-like shapes (Fig. 13 b-c) [34]. These crystals appeared as twofaced basal pinacoids of the hexagonal system [31].

EDS mapping showed that $\mathrm{Cu}$, like $\mathrm{Pb}$, was mainly attached to calcium aluminate compounds rather than to silicon-rich components (Fig. 14).

The scenario after performing curing 2 posed a completely different phase assemblage, in comparison with either $\mathrm{Pb}$ - or $\mathrm{Zn}$-doped samples. The addition of $\mathrm{Cu}$ inhibited the formation of stable hydrated compounds. Metastable hydrates $\left(\mathrm{CAH}_{10}\right)$ could mainly be identified by XRD (Fig. 3). Only after 14 curing days could scarce amounts of stable hydrates be detected. The PSD (Fig. 15) showed the pattern of the metastable hydrates, with the main porosity below $0.5 \mu \mathrm{m}$. Over time, the hydration progress allowed the largest pores to be filled with hydration products. The interparticle space (pores at ca. 2 $\mu \mathrm{m}$, as in 7-days aged sample) disappeared and the pore size shifted towards lower diameters (samples aged 14 and 28 days). These samples with the finest porosity attained the largest compressive strengths among all the mortars tested. The large degree of compactness of the sample was observed by SEM (Fig. 13 d). The textural 
characteristics of this sample resemble those obtained in Zn-CAC mortars but under curing 1, showing different gel-like layers with reduced porosity owing to the formation of metastable hydrates. The high compressive strengths achieved are promising for the use of CAC as a disposal method for $\mathrm{Cu}$-compounds, even though a foreseeable partial decrease in the mechanical strength can be expected due to the long-term conversion reaction.

To conclude, three different patterns of PSD could be related to both the XRD phase assemblage and the mechanical strengths: (i) the first pattern reflected the PSD of anhydrous compounds, in which the finest porosity did not appear. The main pore size was around $2 \mu \mathrm{m}$; (ii) the second pattern accounted for the presence of metastable hydrates, with the majority of the pore population below $0.5 \mu \mathrm{m}$ and a significant number of pores $<0.1 \mu \mathrm{m}$. These samples are of reduced overall porosity; and (iii) finally, the third pattern appeared when stable hydrates crystallized, with average pore diameter between 1 and $1.5 \mu \mathrm{m}$ and a reduced population of pores $<0.5 \mu \mathrm{m}$ in diameter. Combined patterns owing to the simultaneous presence of anhydrous particles and/or metastable and/or stable hydrates could also appear.

\subsection{Sorption studies.}

The effectiveness of the CAC in the uptake of the toxic metals was assessed by batch sorption studies. Adsorption isotherms are depicted in Fig. 16a.

The uptake of $\mathrm{Pb}$ and $\mathrm{Zn}$ (Fig. 16a) fitted to a similar pattern (up to a $3 \% \mathrm{w} / \mathrm{w}$ metal/cement was fully retained by the $\mathrm{CAC}$ ). The uptake of $\mathrm{Cu}$ was the highest, achieving a value as large as 5\% of metal totally retained. CAC was found to be a good sorbent material for these metals. 
Best adjustment of data (Table 2) was found for the Langmuir model [35] that states: (i) the sorption takes place at homogenous sites in the sorbent material; (ii) there is no interaction between the ions, and (iii) the metal is sorbed forming a monolayer coverage on the adsorbent surface.

The adsorption capacities of these metals in CAC $\left(\mathrm{q}_{\mathrm{m}}\right.$, Table 2$)$ are among the best sorption values reported in analogous sorbent materials. For example, maximum adsorption values for $\mathrm{Cu}, \mathrm{Zn}$ and $\mathrm{Pb}$ of $23.25,12.85$ and $27.03 \mathrm{mg}$ per $\mathrm{g}$ of zeolitePortland cement admixtures were reported [36]. Copper retention was greater than that reported for natural kaolin, zeolite and derived geopolymers [37]. These sorption capacities encourage the use of CAC-based systems as an effective toxic metal removal agent.

Careful examination by XRD of solid compounds obtained after sorption studies was executed looking for new metal-bearing compounds that could account for the metal fixation in CAC mortars. The low amount of the compounds and/or the poor crystalline state hindered the proper identification of the compounds, so the results below should be considered cautiously. The addition of either $\mathrm{Pb}$ or $\mathrm{Cu}$ salts gave rise to the presence of anhydrous calcium aluminate phases $\left(\mathrm{CA}\right.$ and $\left.\mathrm{C}_{12} \mathrm{~A}_{7}\right)$ (Fig. 17). Considering the largely alkaline $\mathrm{pH}$ of the cement solutions and the Pourbaix-type diagrams, the geochemical modelling carried out in some previous works reported the formation of hydroxylated and hydroxycarbonated compounds as the phases with the highest likelihood to be found [38]. Additionally, for example, in the presence of $\mathrm{Pb}$, hydrocerussite $\left(\mathrm{Pb}_{3}\left(\mathrm{CO}_{3}\right)_{2}(\mathrm{OH})_{2}\right)$ [38] and $\mathrm{Pb}(\mathrm{OH})_{2}$ [39-42] were found. Therefore, in the current work, it could be reasonably expected the formation of small amounts of similar hydroxylated and hydroxycarbonated compounds of $\mathrm{Cu}$ and $\mathrm{Pb}$. 
By XRD (Fig. 17), it could be seen, in the case of copper, $\mathrm{Cu}(\mathrm{OH})_{2}$ and $\mathrm{Cu}_{4}\left(\mathrm{NO}_{3}\right)_{2}(\mathrm{OH})_{6}$. Additionally, by FTIR-ATR (Figure 18a), the appearance of an absorption band (ca. $3500 \mathrm{~cm}^{-1}$ ), which can be assigned to the $\mathrm{OH}$ stretching mode, could be seen in $\mathrm{Cu}$-samples compared to metal-free samples. This fact is helpful to confirm the presence of a $\mathrm{Cu}(\mathrm{OH})_{2}$ precipitate.

In the case of $\mathrm{Pb}$, small amounts of $\mathrm{Pb}(\mathrm{OH})_{2}$ and hydrocerussite $\left(\mathrm{Pb}_{3}\left(\mathrm{CO}_{3}\right)_{2}(\mathrm{OH})_{2}\right)$ could be identified by XRD (Fig. 17). In Fig. 18b, FTIR-ATR showed at ca. $1400 \mathrm{~cm}^{-1}$ the $v_{3}$ stretching vibrations of the $\mathrm{CO}_{3}{ }^{2-}$ ion that can be assigned to the presence of hydrocerussite [43]. This band only appeared upon the sorption of $\mathrm{Pb}$ : as a matter of fact, in the free-metal sample (control group) this band could not be observed.

Conversely, no specific hydroxylated compounds could be found for Zn. Only after the addition of $10 \mathrm{wt} . \%$ of $\mathrm{Zn}$, some weak diffraction peaks that could be related to a zinc aluminium sulphate hydrate $\left(5 \mathrm{ZnO} \mathrm{Al}_{2} \mathrm{O}_{3} \cdot \mathrm{ZnSO}_{4} \cdot 15 \mathrm{H}_{2} \mathrm{O}\right)$ could be identified (Fig. 17). However, other identification methods were not able to identify this compound, so that its presence remains uncertain.

In good agreement with the findings of the current work, the experimental differences between $\mathrm{Zn}$ and the other two cations $(\mathrm{Cu}$ or $\mathrm{Pb})$ were also recognized in a previous work by Hale et al. [42], who reported that, at high $\mathrm{pH}$ (cement media), $\mathrm{Cu}$ and $\mathrm{Pb}$ hydroxides were the most likely precipitates controlling metal mobility. However, these authors reported differences in cement systems with respect to the $\mathrm{Zn}$ immobilisation, which was not suitably predicted by $\mathrm{Zn}(\mathrm{OH})_{2}$.

In the current work, the XRD and FTIR-ATR results and the good experimental adjustment to the Langmuir model suggest that metals (specially $\mathrm{Cu}$ and $\mathrm{Pb}$ ) could form hydroxo species that can be sorbed to the surface of the CAC [44]. 


\subsection{Assessment of the metal-CAC interaction}

The scientific literature provides controversial results concerning the effects of alkaline, alkaline-earth and transition metal chlorides onto CAC [15,17]. The massive precipitation of a protective gel coating on the phase boundary of anhydrous cement particles would explain the retardation effect of transition metal chlorides. The coating could be formed by amorphous hydroxides and/or double-layer hydroxide phases. This possibility agrees well with the behavior observed for CAC samples doped with $\mathrm{Cu}$ and $\mathrm{Pb}$ nitrates, which showed a strong retardation effect.

The opposite results were found for samples doped with $\mathrm{Zn}\left(\mathrm{NO}_{3}\right)_{2}$. While $\mathrm{ZnCl}_{2}$ was seen to strongly delay the hydration of iron-rich CAC exhibiting the largest reduction in strength [15], the addition of $\mathrm{Zn}\left(\mathrm{NO}_{3}\right)_{2}$ in this research was shown to accelerate the setting of the CAC cements with a moderate reduction in strength. In an iron-lean CAC, transition metal chlorides also showed an accelerating effect [20]. Although the differences in the iron-content of CAC were put forward to justify the discrepancy [15], in the current paper the studies were conducted by using an iron-rich CAC (17 wt.\% of $\left.\mathrm{Fe}_{2} \mathrm{O}_{3}\right)$. The observed differences in the role of $\mathrm{Zn}\left(\mathrm{NO}_{3}\right)_{2}$ with respect to reported data for $\mathrm{ZnCl}_{2}$ might be thought to be due to the effect of counter-ion, because chloride had been identified as a strong retarder for CAC [16]. Besides, the retarding effect of chloride as counter-ion was recently recognized in calcium sulfoaluminate cements [19].

Differences between $\mathrm{Zn}$ and the other two metals could be justified by the precipitation of amorphous gel coating of the cement particles. Hydroxides of both $\mathrm{Pb}$ and $\mathrm{Cu}$ showed less amphoteric character than zinc hydroxide (more soluble in the form of 
$\mathrm{ZnO}_{2}{ }^{2-}$ ), so the former were more likely to appear as precipitates bound to CAC particles, as confirmed by the XRD (Fig. 17) and elemental mapping results. This would explain the delay in the CAC hydration caused by the presence of copper (to a greater extent because of its low amphoteric character) or lead (to a lesser extent by its higher amphoteric character in relation to $\mathrm{Cu}$ ). These facts are in line with those published for CAC [15] as well as for OPC [45].

From the current experimental results, it may be so far suggested that the presence of zinc nitrate induced the preferential formation of $\mathrm{C}_{2} \mathrm{AH}_{8}$ rather than $\mathrm{CAH}_{10}$, as seen by $\mathrm{XRD}$, with the advantageous subsequent effect of improving nucleation rates, in accordance with previous studies $[20,32,46]$. As in the case of lithium, Zn, which

among the three assayed cations showed the highest preference for 4-tetrahedral coordination, would act by promoting nucleation sites for the growth of similarly fourcoordinated structures, as evidenced by the preferential formation of the tetrahedrally coordinated $\mathrm{C}_{2} \mathrm{AH}_{8}$ [47]. On the contrary, $\mathrm{C}_{2} \mathrm{AH}_{8}$ compound was barely found on the addition of either $\mathrm{Cu}$ or $\mathrm{Pb}$, which preferred other different coordination geometries. In the case of $\mathrm{Cu}(\mathrm{II})$, for example, Jahn-Teller distorted octahedral arrangements have been described [48]. The heterogeneous nucleation could shorten the induction period, thus accelerating the hardening process.

\subsection{Leaching tests}

Leaching studies of monolithic mortars showed that, regardless of the curing process, $\mathrm{Cu}$ and $\mathrm{Pb}$ were fully retained in the $\mathrm{CAC}$ matrix, while very low amounts of $\mathrm{Zn}$ could be found in the leachates. Copper and lead, which formed less amphoteric, and so less soluble, hydroxides were totally encapsulated in the CAC mortars. 
In the CAC matrices assayed, $\mathrm{Zn}$ showed $99.99 \%$ retention. The maximum cumulative leaching value obtained after 64 days was ca. 0.49 (mortars under curing 1) and 0.38 (curing 2) mg. $\mathrm{m}^{-2}$, for $\mathrm{Zn}$, complying with the limits imposed by a regulatory norm (800 mg.m $\mathrm{m}^{-2}$, for $\mathrm{Zn}$ ) [49]. As for $\mathrm{Pb}$ and $\mathrm{Cu}$, these limits (400 and $98 \mathrm{mg} \cdot \mathrm{m}^{-2}$, for $\mathrm{Pb}$ and $\mathrm{Cu}$, respectively) were totally fulfilled showing $100 \%$ retention for both metals.

Through a linear regression analysis, the slopes from the cumulative log-log data evaluation were calculated (Table 3) [5]. In Zn-doped mortars subjected to curing 1, the overall leaching process was governed by a dissolution process (slope value 0.758 , time increment 2-7). At the very early stages (time increment 1-4), a delayed diffusion, followed by dissolution and diffusion at the final stages, took place, according to the slope values. For mortars hardened in curing condition 2 , the overall process of the $\mathrm{Zn}$ leaching was controlled by diffusion (slope 0.520, time increment 2-7), a delayed diffusion at early stages and diffusion over the next periods. The absence, at the very early stages, of a surface wash-off process (rapid release of the pollutant owing to the dissolution of the soluble material that exists on the surface of the waste matrix) ensured a good encapsulation of the metal [50].

Both the leaching pattern and the maximum cumulative leaching values were slightly more favourable in the case of samples after curing 2. The formation of a microstructure with stable hydrates (curing 2) was beneficial for improving the Zn retention.

By comparison with OPC and similar binding matrices, toxic metals were better retained in CAC mortars. In OPC mortars metal retention values ranged from 99.82 to 99.97\% for $\mathrm{Pb}$, from 99.85 to $99.91 \%$ for $\mathrm{Zn}$ and from 99.96 to $99.99 \%$ for $\mathrm{Cu}$ [51]; in magnesium phosphate cements, retention levels higher than $99 \%$ for $\mathrm{Pb}$ and higher than $95 \%$ for $\mathrm{Zn}$ and $\mathrm{Cu}$ were reported [52] and retention values of $81 \%$ and $87 \%$ for $\mathrm{Pb}$ and 
$\mathrm{Zn}$ were reported for toxic metals immobilized by cement rotary-kiln co-processing [53]. In this study, the use of CAC clearly enhanced all the values that had previously been reported.

\section{CONCLUSIONS}

Under the curing condition of $20^{\circ} \mathrm{C} / 95 \% \mathrm{RH}, \mathrm{Pb}$ and -specially- $\mathrm{Cu}$ nitrates hampered the hydration process of CAC, yielding anhydrous compounds and showing low mechanical strength. Unlike the effect reported in OPC mortars, $\mathrm{Zn}\left(\mathrm{NO}_{3}\right)_{2}$ caused a dramatic reduction in the workable life, which was reduced by ca. $90 \%$. Metastable $\mathrm{C}_{2} \mathrm{AH}_{8}$ hydrate appeared as the prevailing compound in Zn-doped CAC mortars. The formation of this phase, owing to the preference of $\mathrm{Zn}$ (II) for tetrahedrally coordinated structures, improved nucleation rates and provided an explanation to the setting time reduction observed.

Curing condition $2\left(60^{\circ} \mathrm{C} / 100 \% \mathrm{RH}\right)$ favored the hydration of the cement particles, improving the compressive strength of $\mathrm{Pb}$ and $\mathrm{Cu}$-loaded mortars. In most of the mortars, mechanical strengths met the requirements of the standards, making the CAC an alternative to toxic waste solidification and landfilling.

In hardened specimens, PSD was related to the XRD phase assemblage and three different PSD patterns were drawn: (i) the PSD of anhydrous compounds, with unimodal distribution and main pore size around $2 \mu \mathrm{m}$; (ii) the pattern that accounted for the presence of metastable hydrates, with samples of reduced overall porosity, major pore population below $0.5 \mu \mathrm{m}$ and significant number of pores $<0.1 \mu \mathrm{m}$; and (iii) the 
PSD pattern when stable hydrates crystallize, with an average pore diameter between 1$1.5 \mu \mathrm{m}$ and a reduced population of pores $<0.5 \mu \mathrm{m}$ of diameter.

CAC showed good sorbent capacities for the toxic metals. Sorption studies proved that the metals were fully retained when added below $3 \% \mathrm{w} / \mathrm{w}$ by cement. The uptake of $\mathrm{Cu}$ was the highest (maximum sorption capacity $\sim 60 \mathrm{mg} / \mathrm{g} \mathrm{CAC}$ ).

After the leaching tests, very high retention values of the metals were obtained: $\mathrm{Cu}$ and $\mathrm{Pb}$ were fully retained in the CAC mortar, while $\mathrm{Zn}$ was retained in $99.99 \%$.

To sum up, CAC mortars were seen to perfectly encapsulate the tested toxic metals, allowing us to explore the use of CAC for waste management.

\section{Acknowledgments}

Ciments Molins for the material supplied. Dr. M.C. Jiménez de Haro (ICMS) for the

SEM analysis. FUNA (Fundación Universitaria de Navarra) for funding under FUNA2012-15108172.

\section{References}

[1] M.A.C. Gollmann, M.M. da Silva, A.B. Masuero, J.H.Z. dos Santos, Stabilization and solidification of $\mathrm{Pb}$ in cement matrices, J. Hazard. Mater. 170 (2010) 507-514.

[2] Q.Y. Chen, M. Tyrer, C.D. Hills, X.M. Yang, P. Carey, Immobilisation of heavy metal in cement-based solidification/stabilisation: a review, Waste Manag. 29 (2009) 390-403.

[3] X.C. Qiao, C.S. Poon, C.R. Cheeseman, Investigation into the stabilization/ solidification performance of Portland cement through cement clinker phases, J. Hazard. Mater. 139 (2007) 238-243. 
[4] Q.Y. Chen, C.D. Hills, M. Tyrer, I. Slipper, H.G. Shen, A. Brough, Characterisation of products of tricalcium silicate hydration in the presence of heavy metals. J. Hazard. Mater. 147 (2007) 817-825.

[5] M. Lasheras-Zubiate, I. Navarro-Blasco, J.M. Fernández, J.I. Álvarez. Encapsulation, solid-phase identification and leaching of toxic metals in cement systems modified by natural biodegradable polymers, J. Hazard. Mater. 233-234 (2012) 7-17

[6] G.E. Voglar, D. Lestan, Efficiency modelling of solification/stabilization of multimetal contaminated industrial soil using cement and additives, J. Hazard. Mater. 192 (2011) 753-762.

[7] G. Zhen, X. Lu, X. Cheng, H. Chen, X. Yan, Y, Zhao, Hydration process of the aluminate $12 \mathrm{CaO} \cdot 7 \mathrm{Al} 2 \mathrm{O} 3$-assisted Portland cement-based solidification/stabilization of sewage sludge, Constr. Build. Mater. 30 (2012) 675-81

[8] G.R. Qian, J. Shi, Y.L. Cao, Y.F. Xu, P.C. Chui, Properties of MSW fly ashcalcium sulfoaluminate cement matrix and stabilization/solidification on heavy metals, J. Hazard. Mater. 152 (2008) 196-203.

[9] Y. Dai, G. Qian, Y. Cao, Y. Chi, Y. Xu, J. Zhou, Q. Liu, Z.P. Xu, S.-Z. Qiao, Effective removal and fixation of $\mathrm{Cr}(\mathrm{VI})$ from aqueous solution with Friedel's salt, J. Hazard. Mater. 170 (2009) 1086-1092.

[10] G. Qian, Y. Cao, P. Chui, J. Tay, Utilization of MSWI fly ash for stabilization/solidification of industrial waste sludge, J. Hazard. Mater. 129 (2006) 274281.

[11] M.C.G. Juenger, F. Winnefeld, J.L. Provis, J.H. Ideker, Advances in alternative cementitious binders, Cem. Concr. Res. 41 (2011) 1232-43.

[12] A.P. Luz, V.C. Pandolfelli, Halting the calcium aluminate cement hydration process, Ceram. Int. 37 (2011) 3789-3793.

[13] B. Pacewska, I. Wilinska, M. Nowacka, Studies on the influence of different fly ashes and Portland cement on early hydration of calcium aluminate cement, J. Therm. Anal. Calorim. 106 (2011) 859-68.

[14] A. Hidalgo, S. Petit, J.L. Garcia, C. Alonso, C. Andrade, Microstructure of the system calcium aluminate cement-silica fume: application in waste immobilization, in: R. Xu, Z. Gao, J. Chen, W. Yan (Eds), From Zeolites to Porous MOF Materials, Elsevier, Amsterdam, 2007, pp. 1617-1628.

[15] N. Ukrainczyk, N. Vrbos, J. Šipušić, Influence of metal chloride salts on calcium aluminate cement hydration, Adv. Cem. Res. 24 (2012) 249-262. 
[16] B.R. Currell, R. Grzeskowlak, H.G. Midgley, J.R. Parsonage, The acceleration and retardation of set high alumina cement by additives, Cem. Concr. Res. 17 (1987) 420432.

[17] S.A. Rodger, D.D. Double, The chemistry of hydration of high alumina cement in the presence of accelerating and retarding admixtures, Cem. Concr. Res. 14 (1984) 7382 .

[18] R. Nithya, S. Barathan, M. Gopalakrishan, G. Sivakumar, B. Gobinath, The Hydration of Heavy Metal Salts Admixtured High Alumina Cement - A X-Ray Diffraction Study, Applied Physics Research 1 (2009) 19-24.

[19] S. Berger, C. Cau Dit Coumes, P. Le Bescop, D. Damidot, Hydration of calcium sulfoaluminate cement by a $\mathrm{ZnCl} 2$ solution: Investigation at early age, Cem. Concr. Res. 39 (2009) 1180-1187.

[20] M. Murat, E.H. Sadok, Role of foreign cations in solution in the hydration kinetics of high alumina cement, in: R.J. Mangabhai (Ed.), Calcium Aluminate Cements. Chapman and Hall, London, 1990, pp. 155-166.

[21] T. Matusinović, S. Kurajica, J. Šipušić, The correlation between compressive strength and ultrasonic parameters of calcium aluminate cement materials, Cem. Concr. Res. 34 (2004) 1451-1457.

[22] E. Sakai, T. Sugiyama, T. Saito, M. Daimon, Mechanical properties and microstructures of calcium aluminate based ultra high strength cement, Cem. Concr. Res. 40 (2010) 966-970.

[23] M. Lasheras-Zubiate, I. Navarro-Blasco, J.I. Álvarez, J.M. Fernández, Interaction of carboxymethylchitosan and heavy metals in cement media, J. Hazard. Mater. 194 (2011) 223-231.

[24] C. Gosselin, E. Gallucci, K. Scrivener, Influence of self heating and Li2SO4 addition on the microstructural development of calcium aluminate cement, Cem. Concr. Res. 40 (2010) 1555-1570.

[25] N.J. Coleman, D.S. Brassington, A. Raza, A.P. Mendham, Sorption of Co2+ and Sr2+ by waste-derived $11 \AA$ A tobermorite, Waste Manage. 26 (2006) 260-267.

[26] EA NEN 7375, Leaching characteristics of moulded or monolithic building and waste materials, Determination of leaching of inorganic components with the diffusion test, 2004.

[27] N. Gineys, G. Aouad, D. Damidot, Managing trace elements in Portland cement Part I: Interactions between cement paste and heavy metals added during mixing as soluble salts, Cem. Concr. Comp. 32 (2010) 563-570. 
[28] B. Pandey, S.D. Kinrade, L.J.J. Catalan, Effects of carbonation on the leachability and compressive strength of cement-solidified and geopolymer-solidified synthetic metal wastes, J. Environ. Manage. 101 (2012) 59-67.

[29] Waste acceptance at landfills, Environment Agency, Bristol, 2010.

[30] ASTM Standard C90, Standard Specification for Loadbearing Concrete Masonry Units, ASTM International, West Conshohocken, PA, 2012, DOI: 10.1520/C0090-12, www.astm.org.

[31] S.K. Das, S. Kumar, P.K. Das Poddar, Crystal morphology of calcium aluminates hydrated for 14 days, J. Mater. Sci. Letters 16 (1997) 735-736.

[32] J.M. Rivas Mercury, A.H. De Aza, X. Turrillas, P. Pena, Hidratación de los cementos de aluminato de calcio (Parte I), Bol. Soc. Esp. Ceram. Vidr. 42 (2003) 269276.

[33] D. Lee, Formation of leadhillite and calcium lead silicate hydrate (C-Pb-S-H) in the solidification/stabilization of lead contaminants, Chemosphere 66 (2007) 1727-1733.

[34] García del Cura, P. Garcés, E. García Alcocel, Petrographical analysis of calcium aluminate cement mortars: Scanning electron microscopy and transmitted light microscopy, Cem. Concr. Res. 29 (1999) 1881-1885.

[35] J.S. Kwon, S.T. Yun, J.H. Lee, S.O. Kim, H.Y. Jo, Removal of divalent heavy metals $(\mathrm{Cd}, \mathrm{Cu}, \mathrm{Pb}$, and $\mathrm{Zn})$ and arsenic(III) from aqueous solutions using scoria: Kinetics and equilibria of sorption, J. Hazard. Mater. 174 (2010) 307-313.

[36] Y.S. Ok, J.E. Yang, Y.S. Zhang, S.J. Kim, D.Y. Chung, Heavy metal adsorption by a formulated zeolite-Portland cement mixture, J. Hazard. Mater. 147 (2007) 91-96.

[37] I.Y. Rushdi, E.E. Bassam, A. Mazen, K. Fawwaz K., Hani, The influence of using Jordanian natural zeolite on the adsorption, physical, and mechanical properties of geopolymers products, J. Hazard. Mater. 165 (2009) 379-387.

[38] E. Martens, D. Jacques, T. Van Gerven, L. Wang, D. Mallants, Geochemical modeling of leaching of $\mathrm{Ca}, \mathrm{Mg}, \mathrm{Al}$, and $\mathrm{Pb}$ from cementitious waste forms, Cem. Concr. Res. 40 (2010) 1298-1305.

[39] C.E. Halim, S.A. Short, J.A. Scott, R. Amal, G. Low, Modelling the leaching of Pb, $\mathrm{Cd}, \mathrm{As}$, and $\mathrm{Cr}$ from cementitious waste using PHREEQC, J. Hazard. Mater. 12 (2005) 45-61.

[40] L. De Windt, R. Badreddine, V. Lagneau, Long-term reactive transport modelling of stabilized/solidified waste: from dynamic leaching tests to disposal scenarios, J. Hazard. Mater. 139 (2007) 529-536. 
[41] C.-Y. Yin, H.B. Mahmud, M. Ghazaly Shaaban, Stabilization/solidification of lead-contaminated soil using cement and rice husk ash, J. Hazard. Mater. 137 (2006) 1758-1764.

[42] B. Hale, L. Evans, R. Lambert, Effects of cement or lime on $\mathrm{Cd}, \mathrm{Co}, \mathrm{Cu}, \mathrm{Ni}, \mathrm{Pb}, \mathrm{Sb}$ and $\mathrm{Zn}$ mobility in field-contaminated and aged soils, J. Hazard. Mater. 199-200 (2012) 119-127.

[43] M.L. Franquelo, A. Duran, L.K. Herrera, M.C. Jimenez de Haro, J.L. PerezRodriguez, Comparison between micro-Raman and micro-FTIR spectroscopy techniques for the characterization of pigments from Southern Spain Cultural Heritage, J. Mol. Struct. 924-926 (2009) 404-412.

[44] A. Sheikhhosseini, M. Shirvani, H. Shariatmadari, Competitive sorption of nickel, cadmium, zinc and copper on palygorskite and sepiolite silicate clay minerals, Geoderma 192 (2013) 249-253.

[45] N.L. Thomas, D.A. Jameson, D.D. Double, The effect of lead nitrate on the early hydration of portland cement, Cem. Concr. Res. 11 (1981) 143-153.

[46] S. Rashid, P. Barnes, J. Bensted, X. Turrillas, Conversion of calcium aluminate cement hydrates re-examined with synchrotron energy-dispersive diffraction, J. Mater. Sci. Letters 13 (1994) 1232-1234.

[47] D. Sorrentino, F. Sorrentino, M. George, Mechanisms of hydration of calcium aluminate cements, in: J. Skalny, S. Mindess, (Eds.), Materials Science of Concrete IV, The American Ceramic Society, Westerville, 1995, pp. 41-90.

[48] A.F. Wells, Structural Inorganic Chemistry, Oxford Press, London, 1962.

[49] Dutch Soil Quality Regulation, 2006.

[50] R.O. Abdel Rahman, A.M. El-Kamash, A.A. Zaki, Modeling the Long Term Leaching Behavior of $137 \mathrm{Cs}, 60 \mathrm{Co}$, and 152,154Eu Radionuclides from Cement- Clay Matrices, J. Hazard. Mater. 145 (2007) 372-380.

[51] Z. Giergiczny, A. Król, Immobilization of heavy metals ( $\mathrm{Pb}, \mathrm{Cu}, \mathrm{Cr}, \mathrm{Zn}, \mathrm{Cd}, \mathrm{Mn})$ in the mineral additions containing concrete composites, J. Hazard. Mater. 160 (2008) 247-255.

[52] I. Buj, J. Torras, M. Rovira, J. de Pablo, Leaching behaviour of magnesium phosphate cements containing high quantities of heavy metals, J. Hazard. Mater. 175 (2010) 789-794.

[53] J. Zhang, J. Liu, C. Li, Y. Jin, Y. Nie, J. Li, Comparison of the fixation effects of heavy metals by cement rotary kiln co-processing and cement based solidification/stabilization, J. Hazard. Mater. 165 (2009) 1179-1185. 

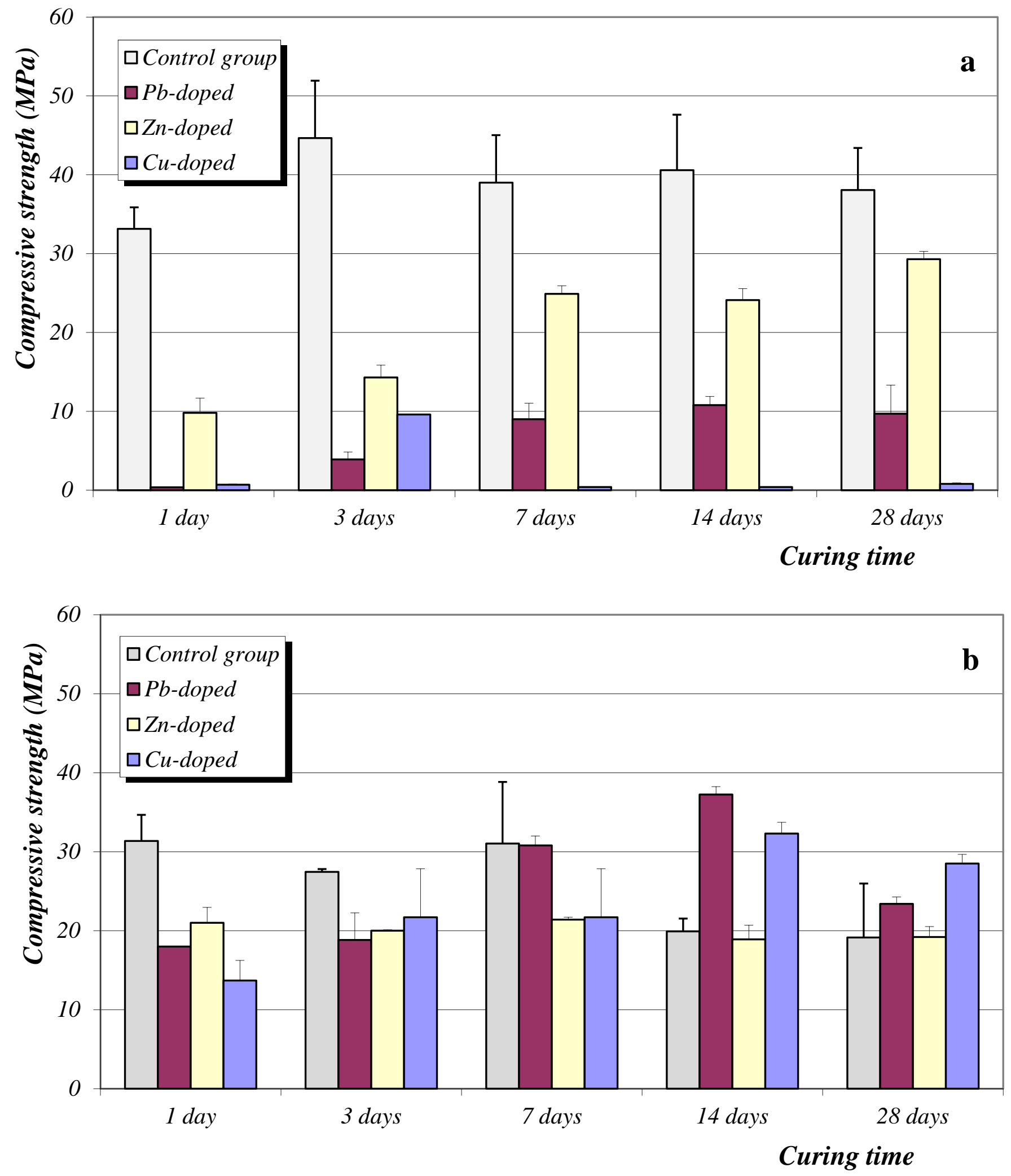

Figure 1. Compressive strengths: a) condition 1; b) condition 2. 

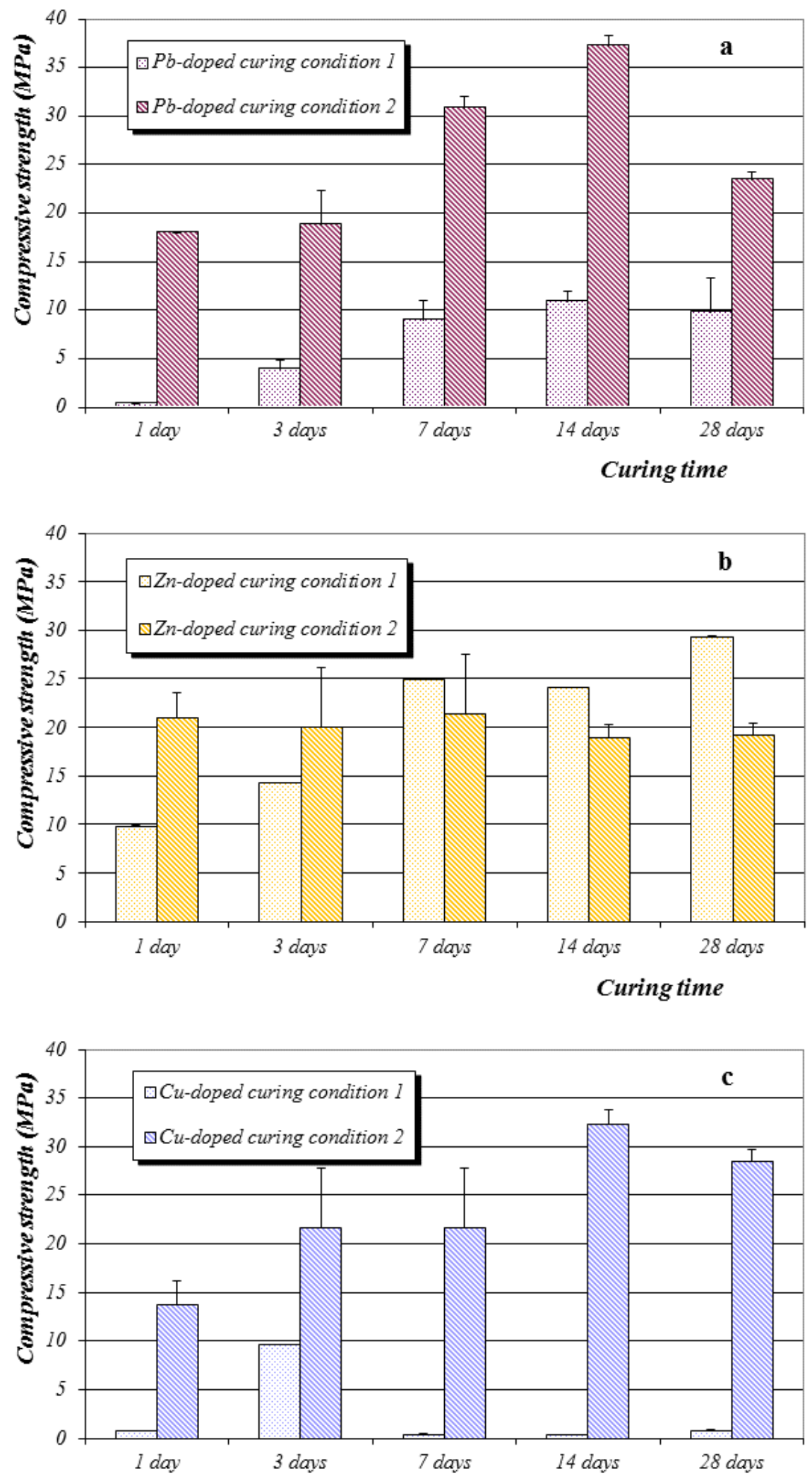

Curing time

Figure 2. Compressive strengths for a) $\mathrm{Pb}-$; b) $\mathrm{Zn}$-; c) Cu-doped samples under conditions 1 and 2 . 


\section{Curing condition 1}
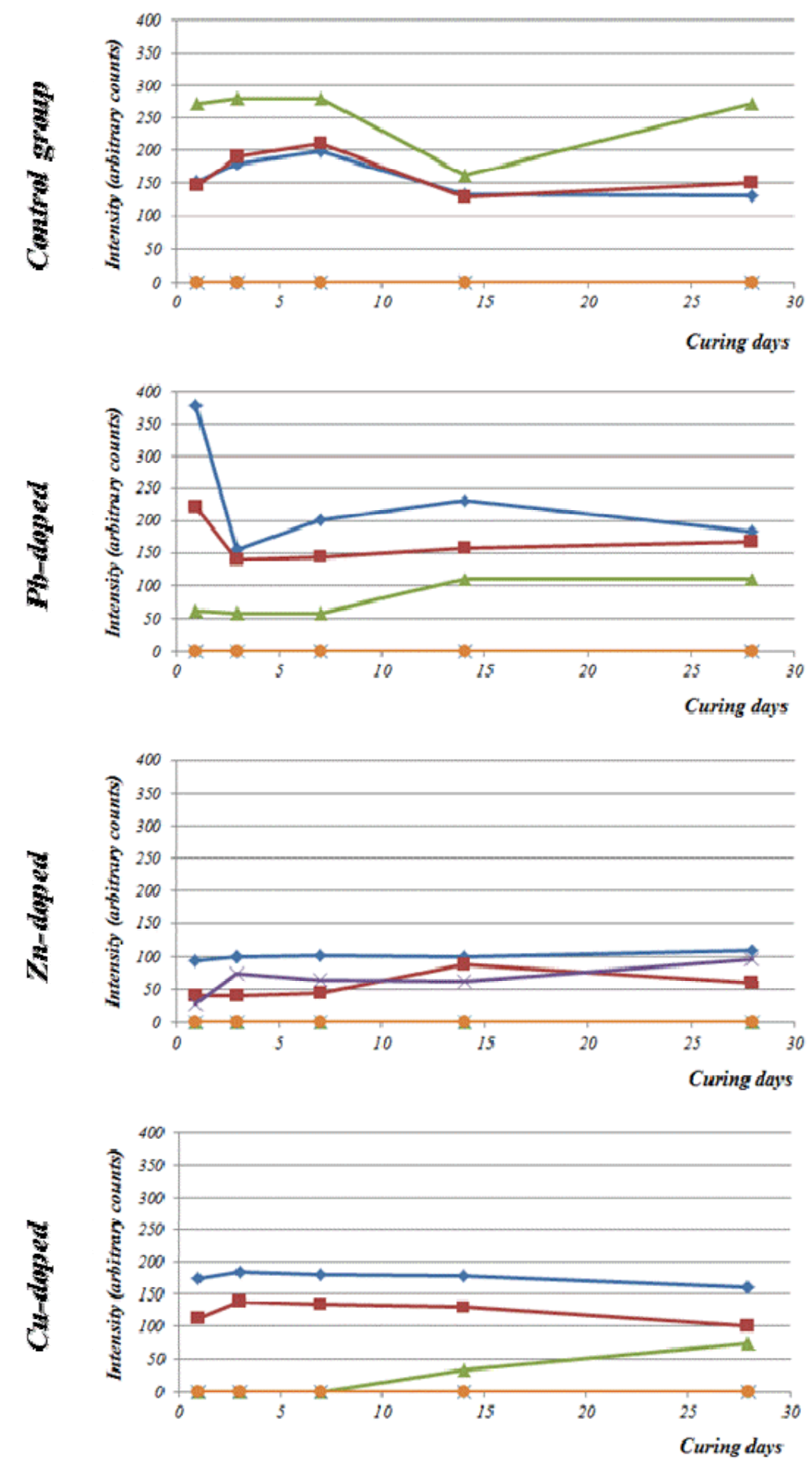

Curing condition 2
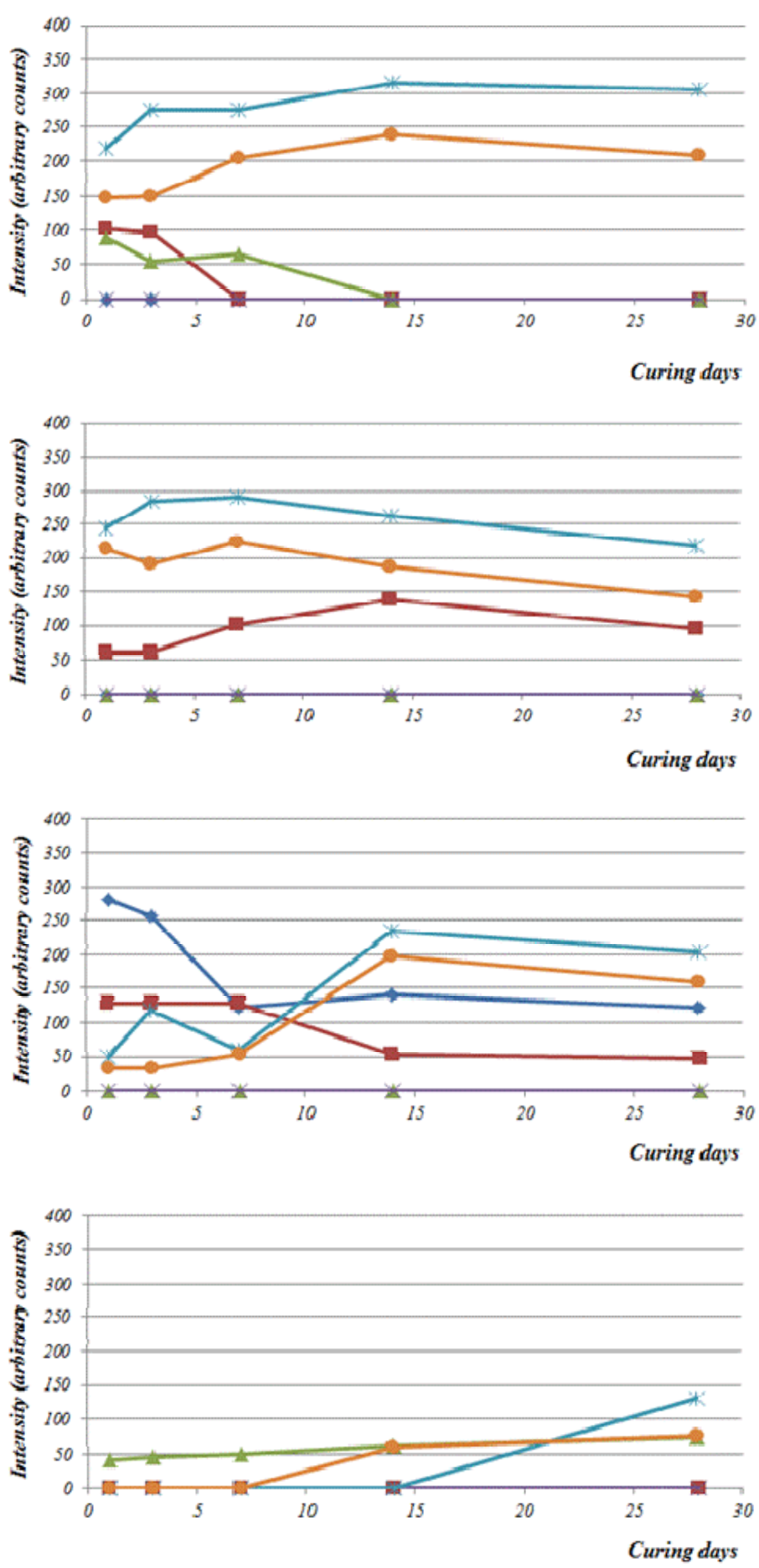

Figure 3. XRD of samples cured under conditions 1 (left) and 2 (right). 


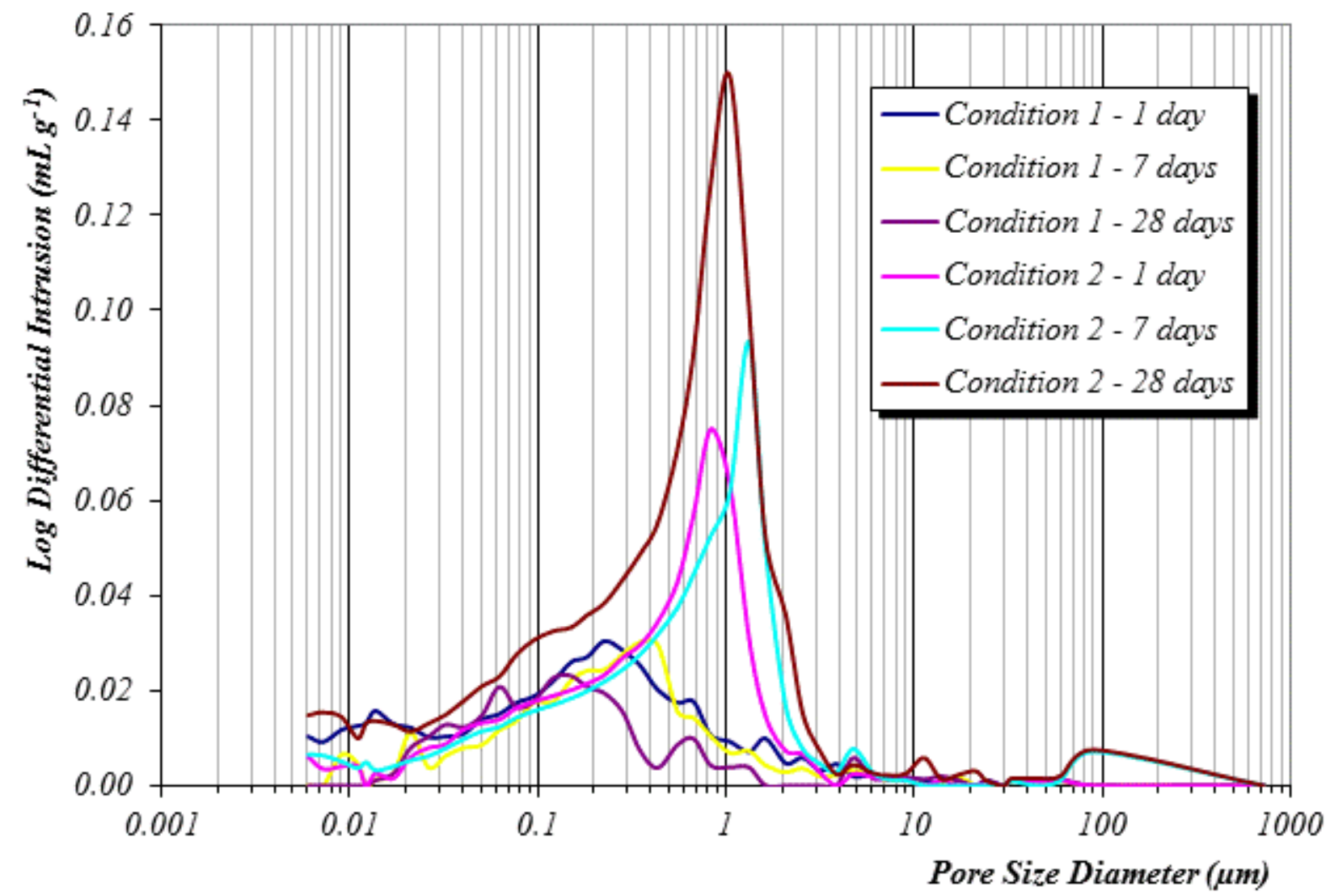

Figure 4. PSD of control samples. 

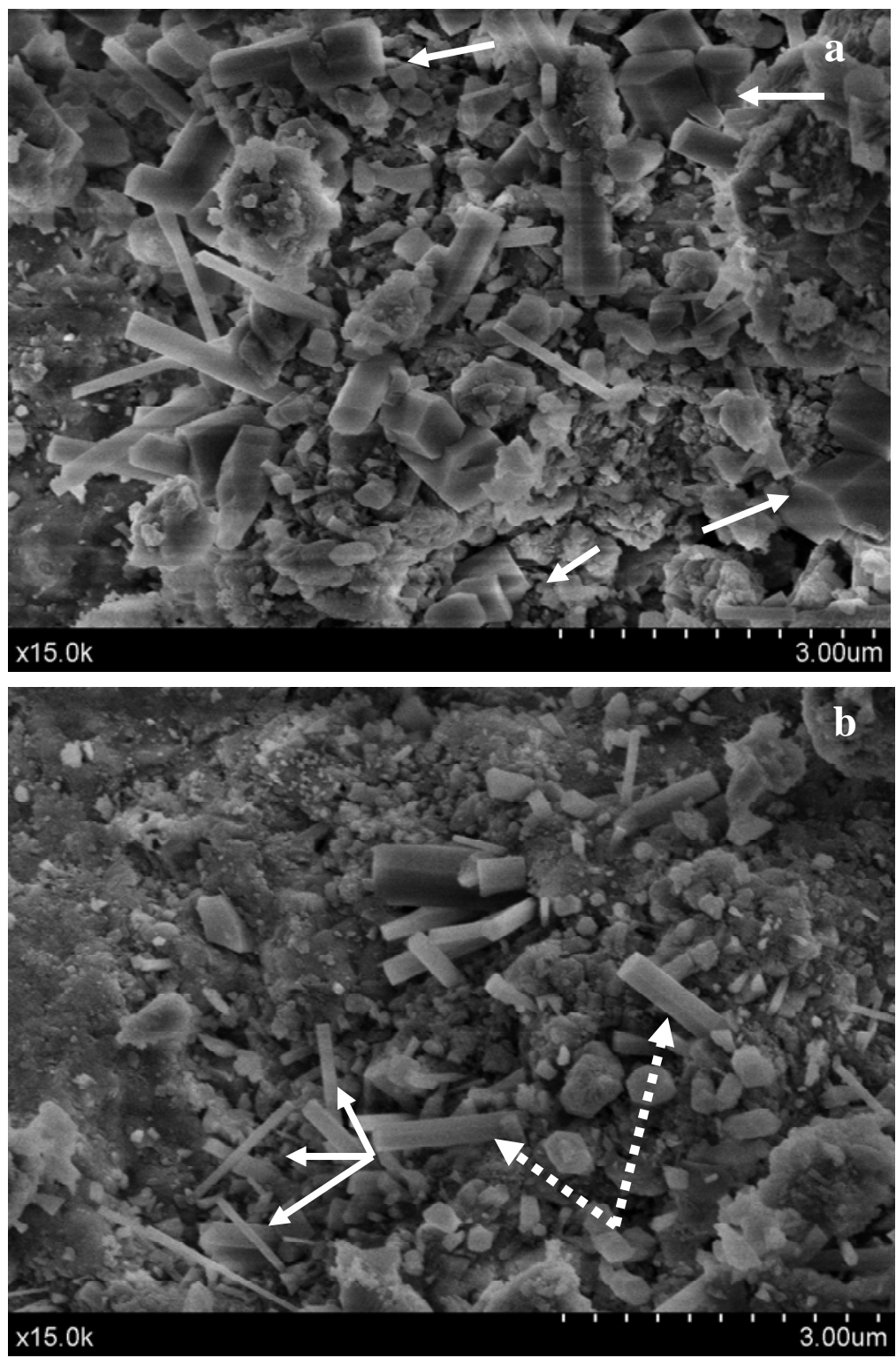

Figure 5. SEM micrographs of 28-days aged control samples (condition 2): a) trapezohedral, rhombo-trapezohedral and cubic-shaped $\mathrm{C}_{3} \mathrm{AH}_{6}$ (arrows); b) $\mathrm{AH}_{3}$ needles (solid arrows) and hexagonal prisms of metastable hydrates (dotted arrows). 


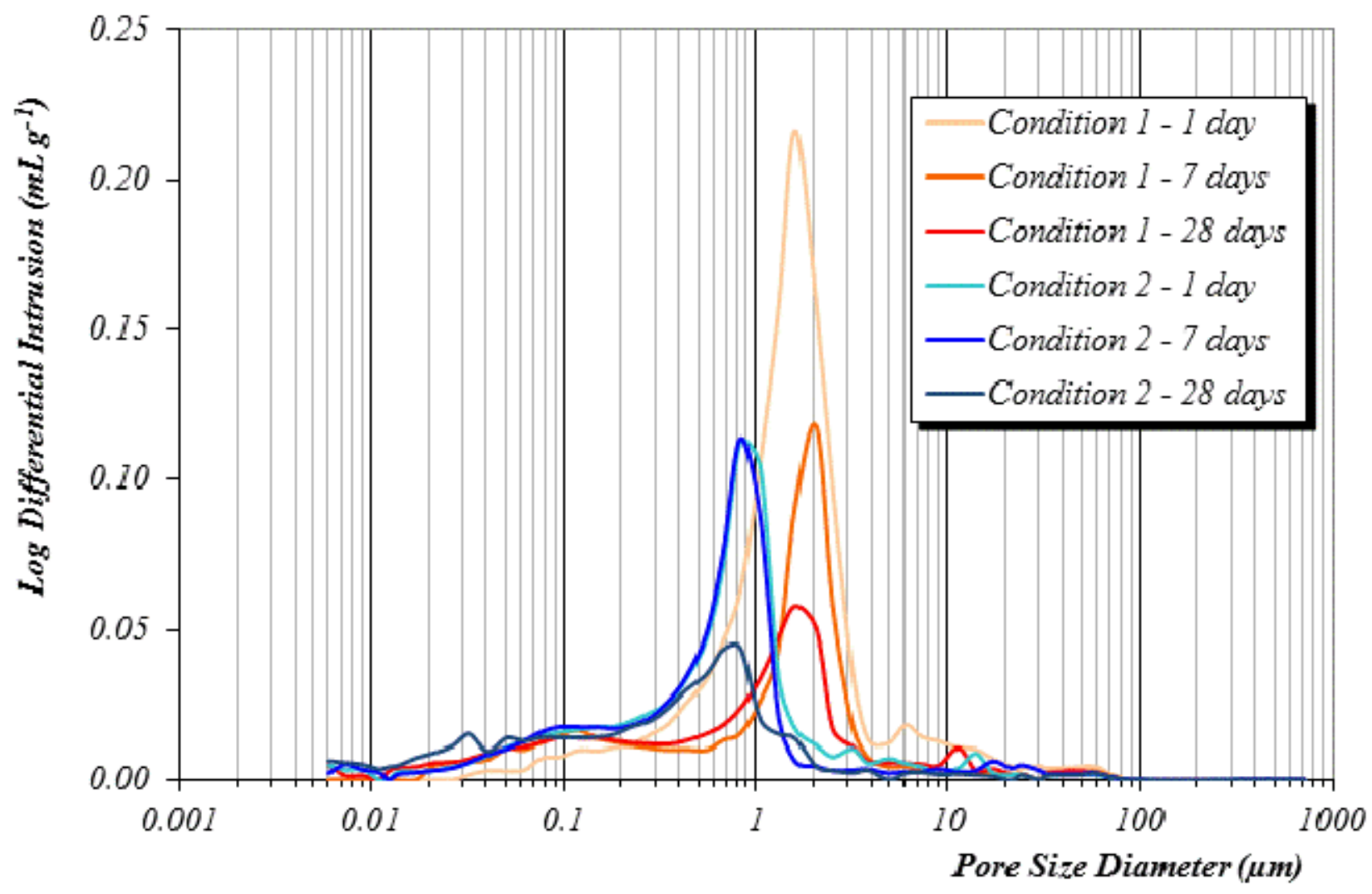

Figure 6. PSD of Pb-doped samples. 

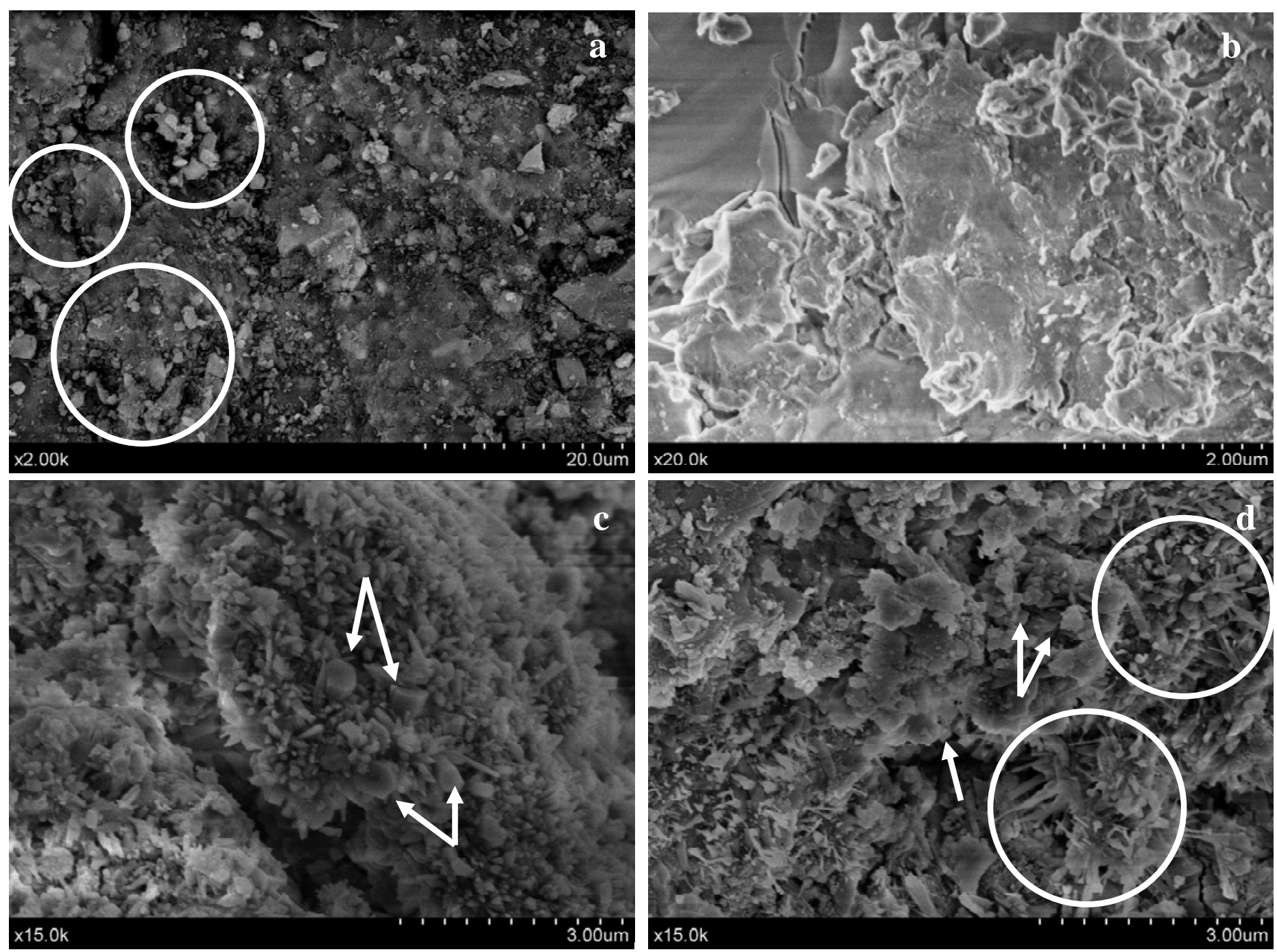

Figure 7. SEM micrographs of Pb-CAC samples cured under condition 1 (a-c) and 2(d): a) anhydrous cement particles (encircled areas) at day $14 ;$ b) gelified metastable hydrates at day 28; c) needles and hexagonally-shaped (arrows) $\mathrm{CAH}_{10}$ crystals at day 28; d) fibrous matrix of $\mathrm{AH}_{3}$ needles (encircled areas) and cubic crystals of $\mathrm{C}_{3} \mathrm{AH}_{6}$ (arrows). 


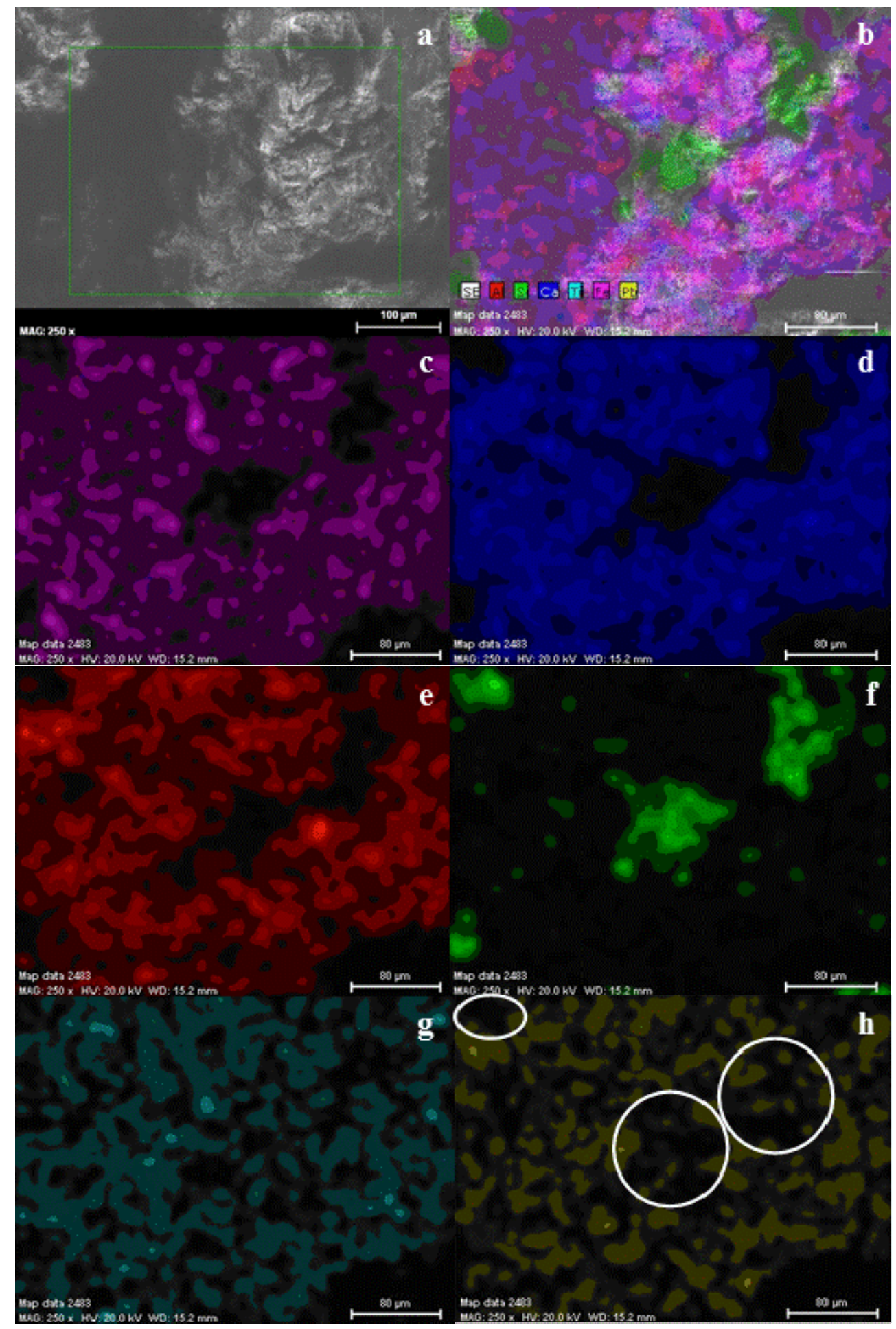

Figure 8. EDS mapping of 28-days aged Pb-doped CAC samples (condition 1): a) SEM micrograph; b) global chemical mapping; c) Fe; d) Ca; e) Al; f) Si; g) Ti; h) Pb. Lean-Pb areas are encircled, corresponding to rich-silicon areas. 


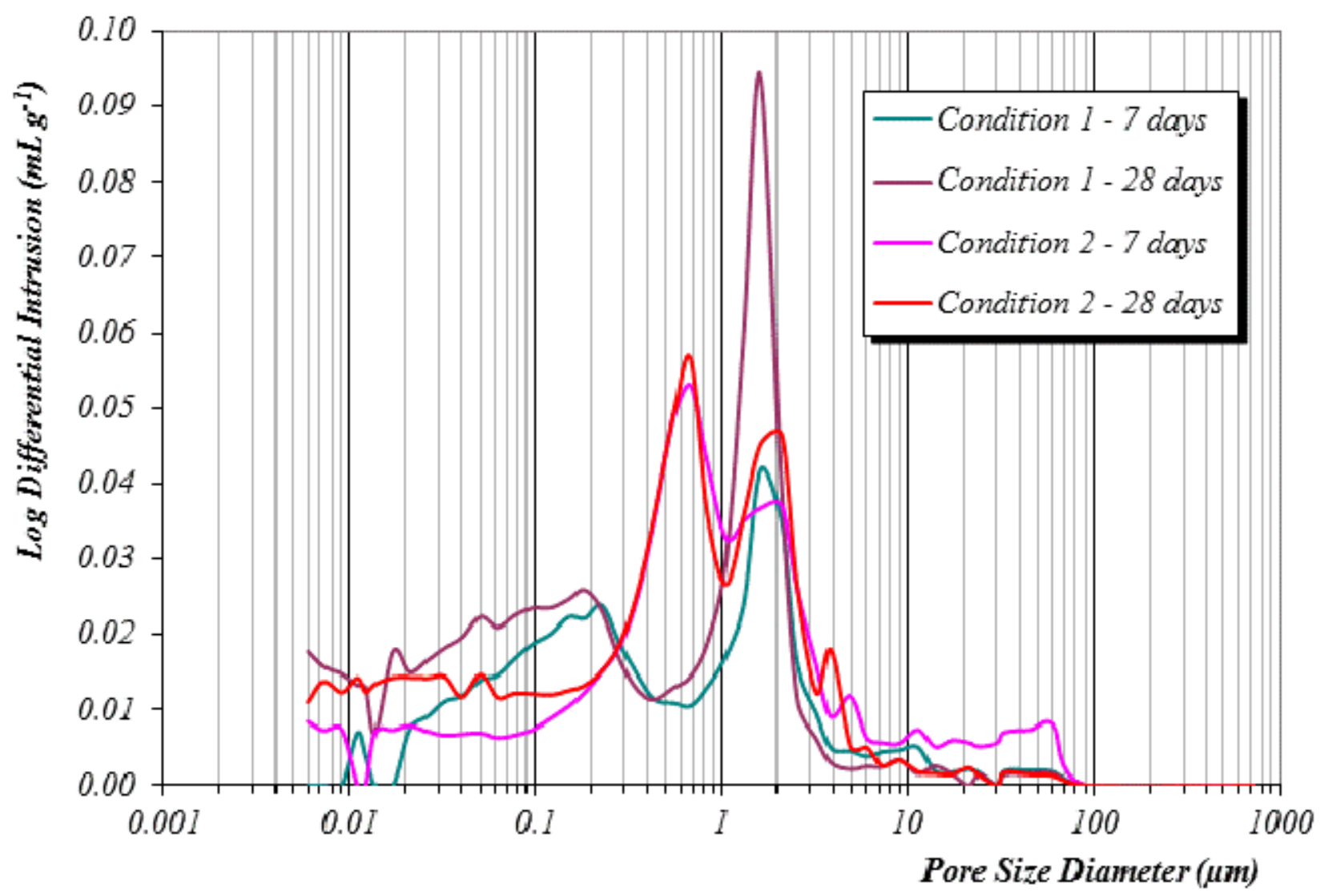

Figure 9. PSD of Zn-doped samples. 

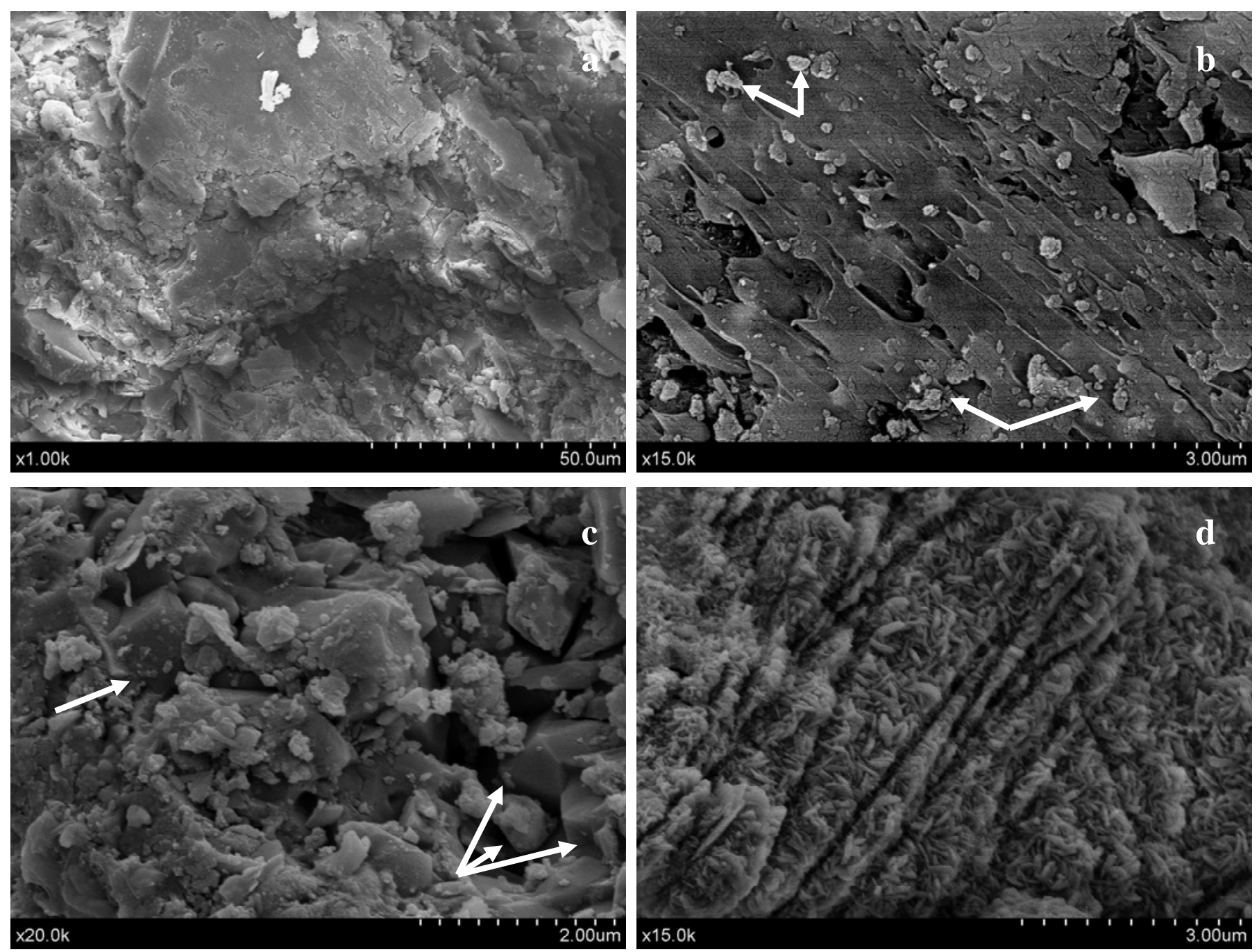

Figure 10. SEM examination of 28-days aged Zn-CAC samples. Condition 1 (a-b) and 2 (c-d): a) gel-like structure of metastable hydrates; b) thin spread out gel-like layers with anhydrous cement particles (arrows); c) $\mathrm{C}_{3} \mathrm{AH}_{6}$ cubic and trapezohedrally-shaped crystals (arrows); d) densely packed $\mathrm{AH}_{3}$ needles. 


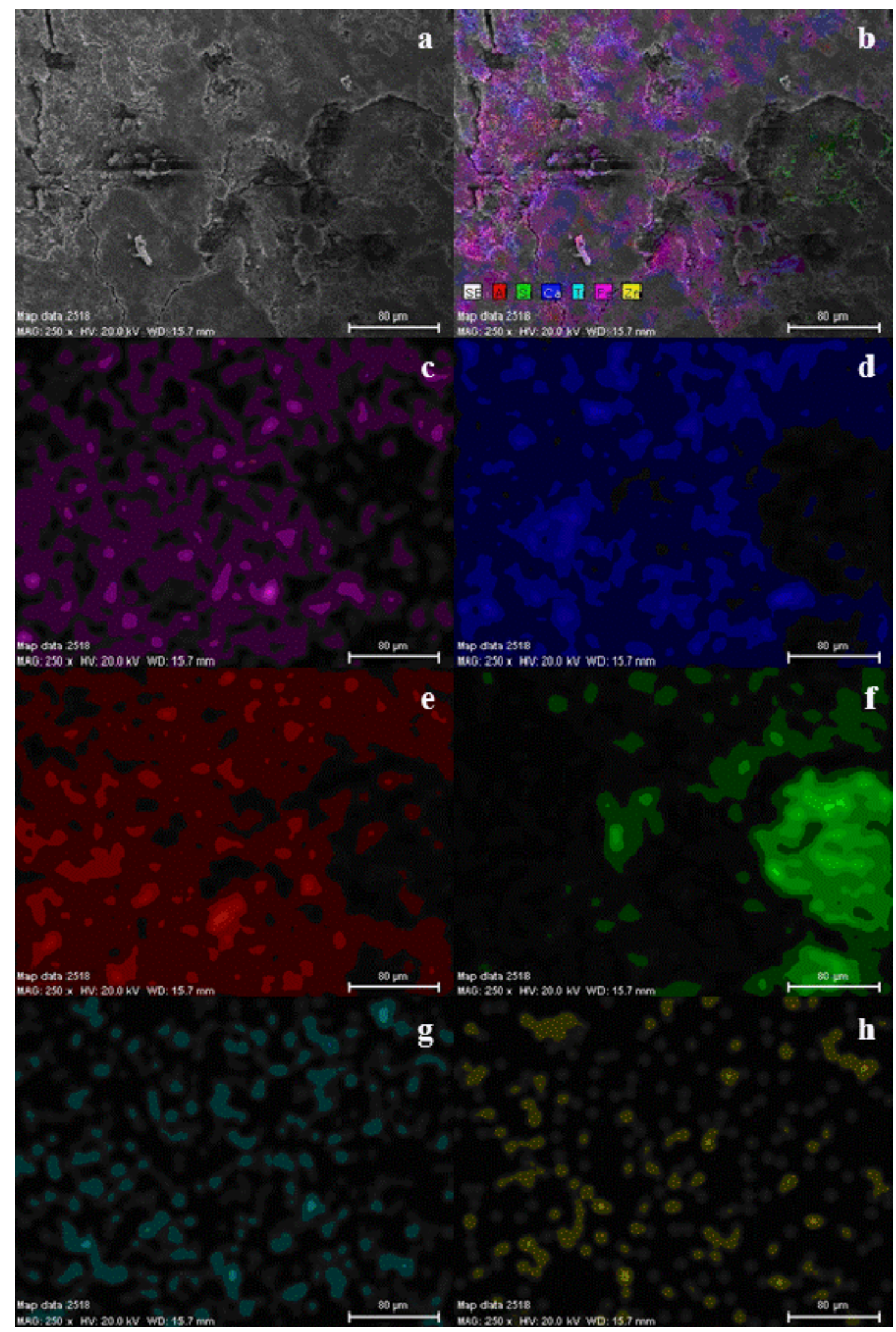

Figure 11. EDS mapping of Zn-doped CAC samples (28 curing days, condition 1): a) SEM micrograph; b) global chemical mapping; c) Fe; d) Ca; e) Al; f) Si; g) Ti; h) Zn. 


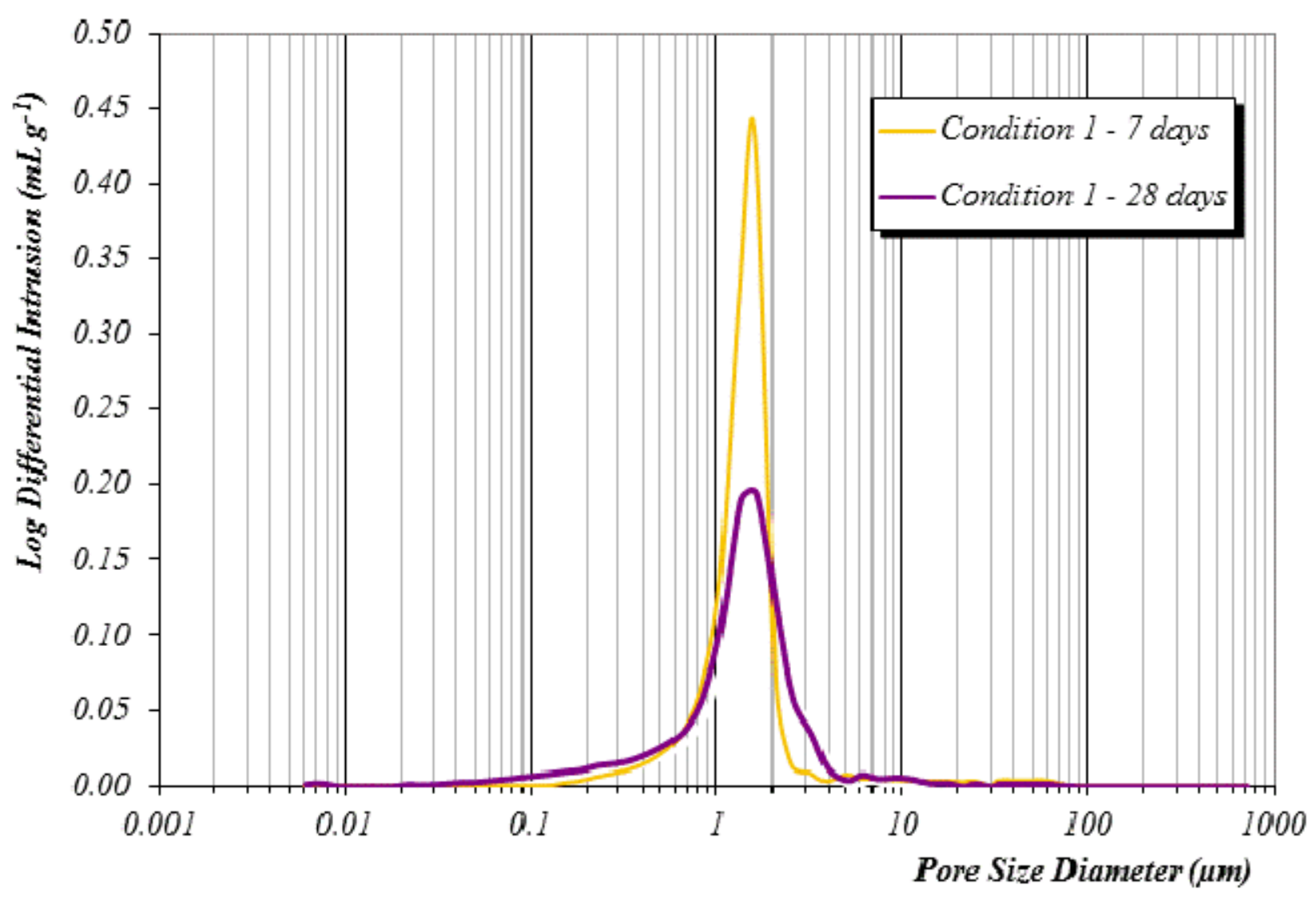

Figure 12. PSD of $\mathrm{Cu}$-doped samples (condition 1). 

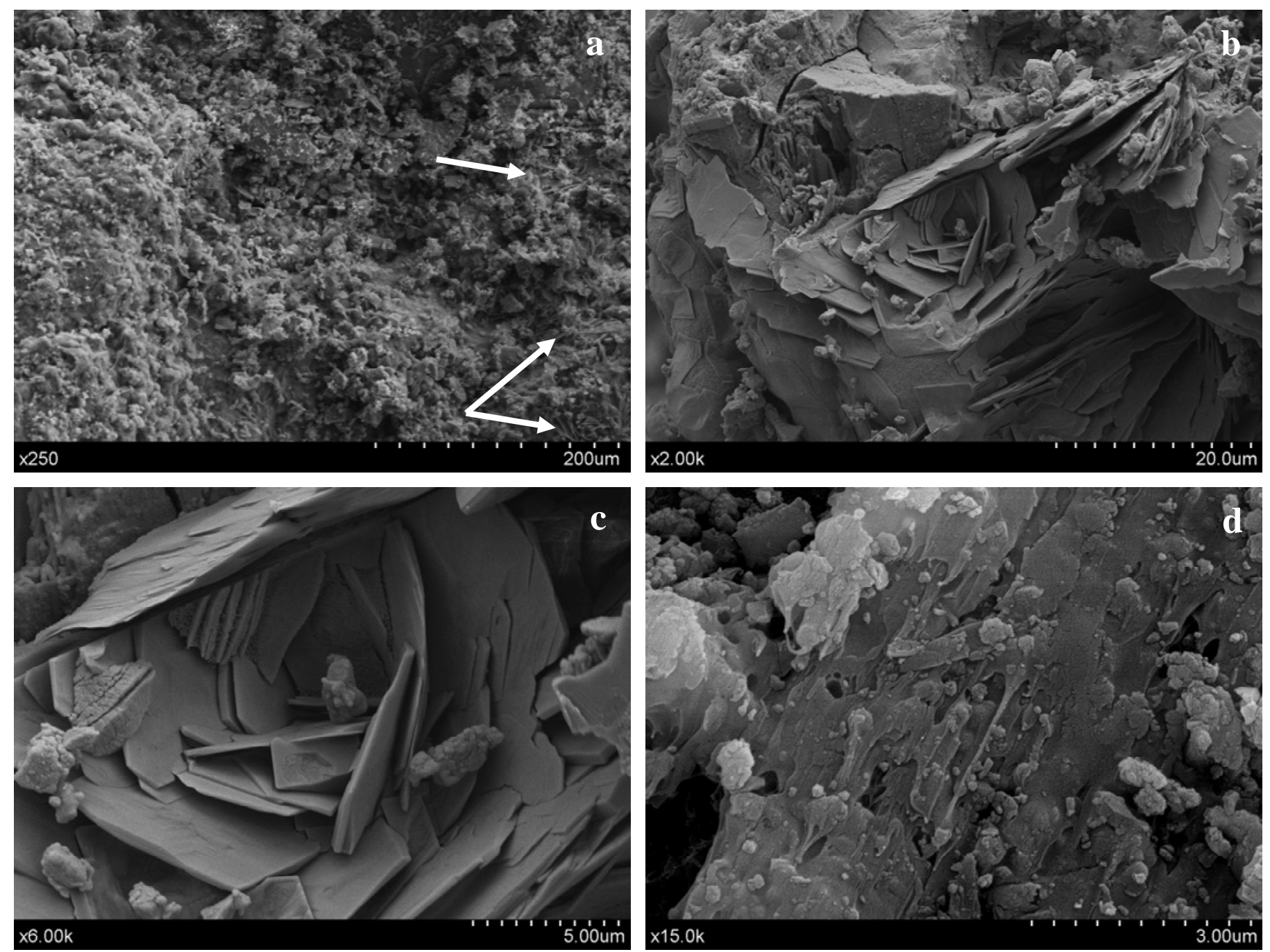

Figure 13. SEM micrographs of 28-days aged $\mathrm{Cu}-\mathrm{CAC}$ samples: Curing condition 1 (ac) and 2 (d). a) Gel-like microstructure with some hexagonal plates (arrows); b) and c) rosette-like structure of $\mathrm{CAH}_{10}$ crystals; d) thin spread out gel-like layers. 


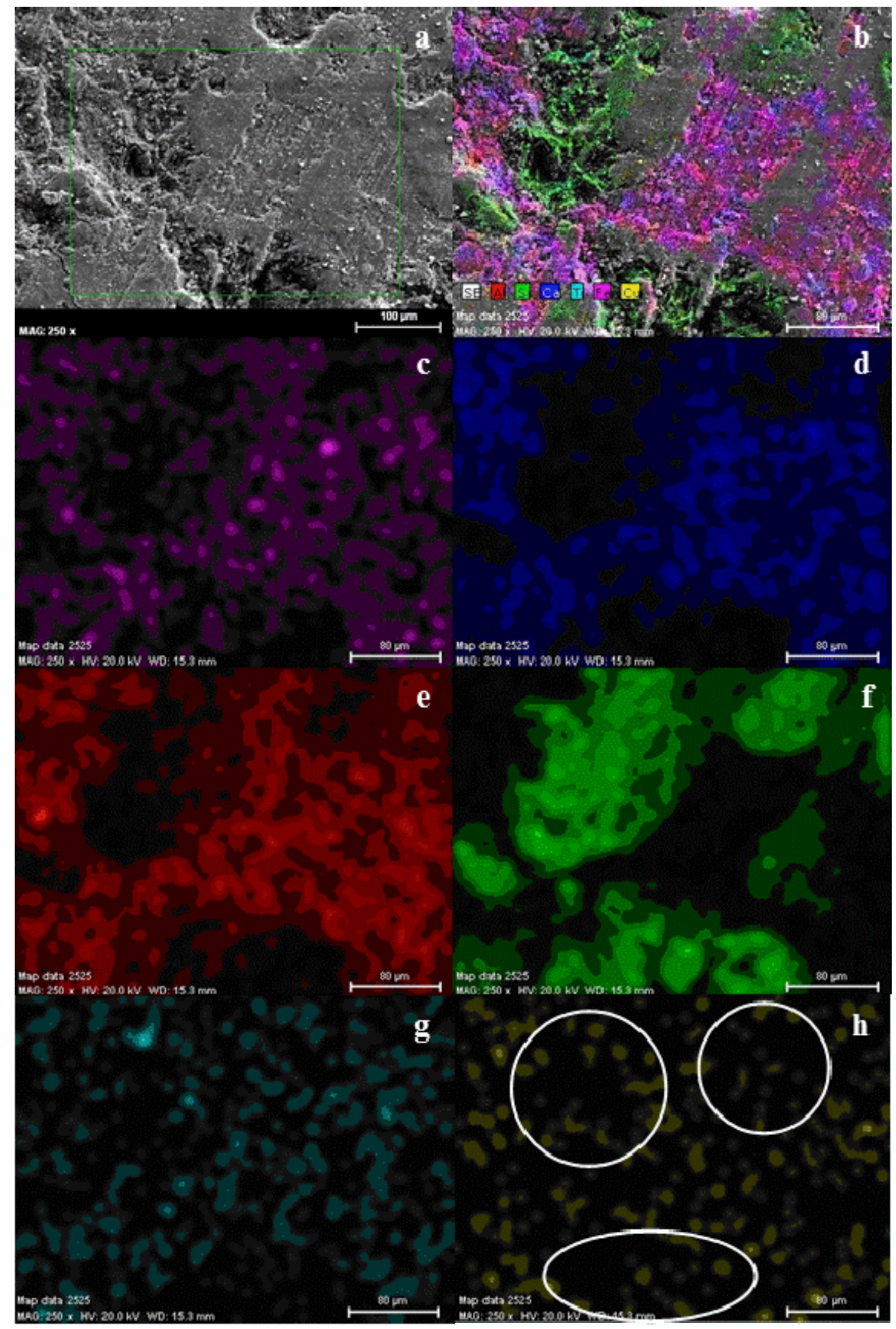

Figure 14. EDS mapping of $\mathrm{Cu}$-doped CAC samples (28 curing days, condition 1): a) SEM micrograph; b) global chemical mapping; c) Fe; d) Ca; e) Al; f) $\mathrm{Si}$; g) $\mathrm{Ti}$; h) $\mathrm{Cu}$. Lean- $\mathrm{Cu}$ areas are encircled, corresponding to Si-rich areas. 


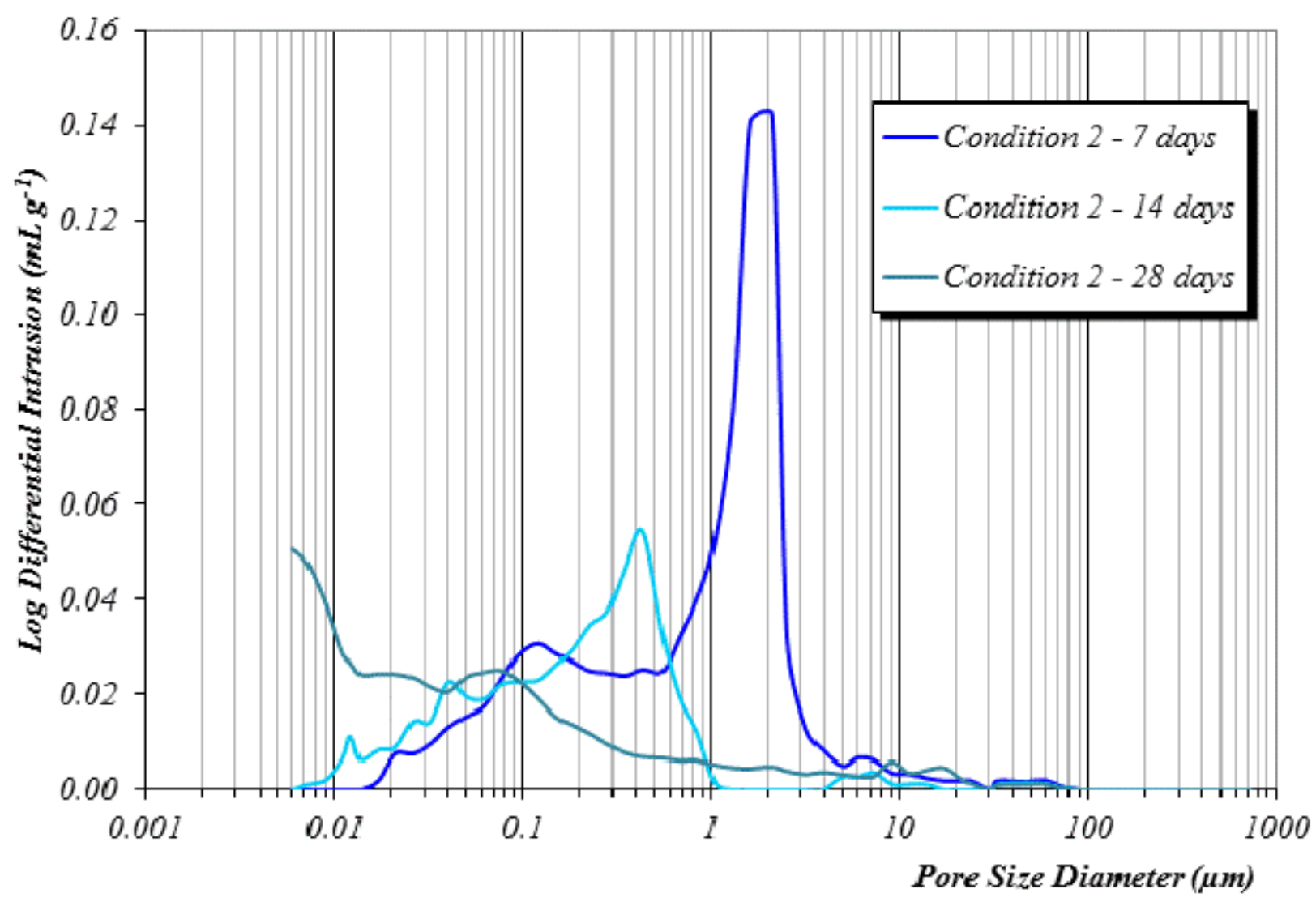

Figure 15. PSD of Cu-doped samples ( condition 2). 

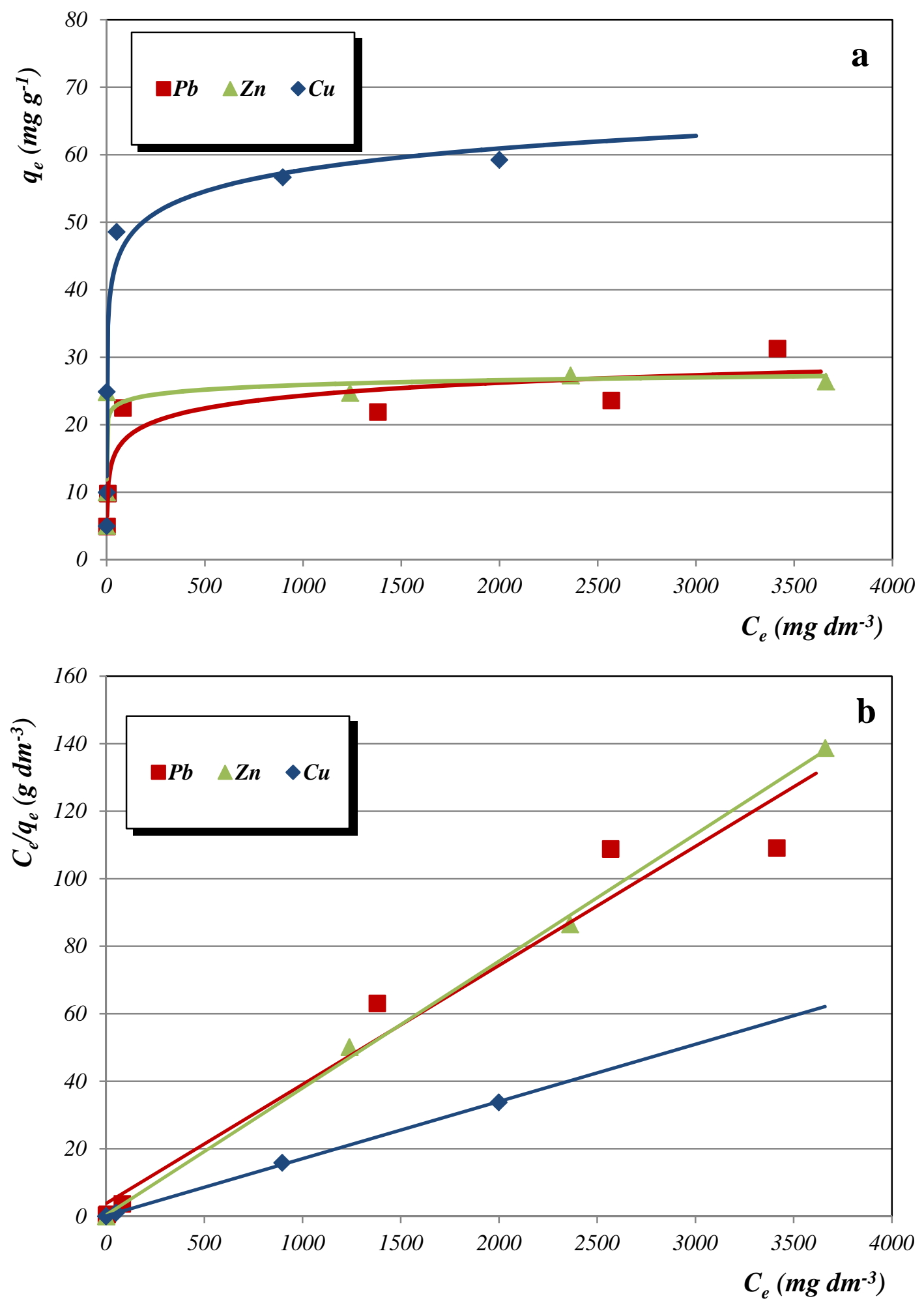

Figure 16. a) Adsorption isotherms; b) linearized algorithm of the Langmuir equation. 
CA: Calctum alumtnum oxtde, $\mathrm{CaAl} 2 \mathrm{O}_{43}$ ICDD 01-070-0134

M: Mayenite, $\mathrm{Ca}_{22} \mathrm{Al}_{24} \mathrm{O}_{33}$ ICDD 00-009-0413

1. Copper nitrate hydroxide, $\mathrm{Cu}_{4}\left(\mathrm{NO}_{3}\right)_{2}(\mathrm{OH})_{6,} \mathrm{ICDD}$ 01-077-0148

2. Copper hydroxide, $\mathrm{Cu}(\mathrm{OH})_{2}, \mathrm{ICDD}$ 00-013-0420

3: Hydrocerussite, $\mathrm{Pb}_{3}\left(\mathrm{CO}_{3}\right)_{2}(\mathrm{OH})_{2}, \mathrm{ICDD}$ 00-013-0I31

4: Lead hydroxide, $\mathrm{Pb}(\mathrm{OH})_{2}, \mathrm{ICDD}$ 00-011-0270

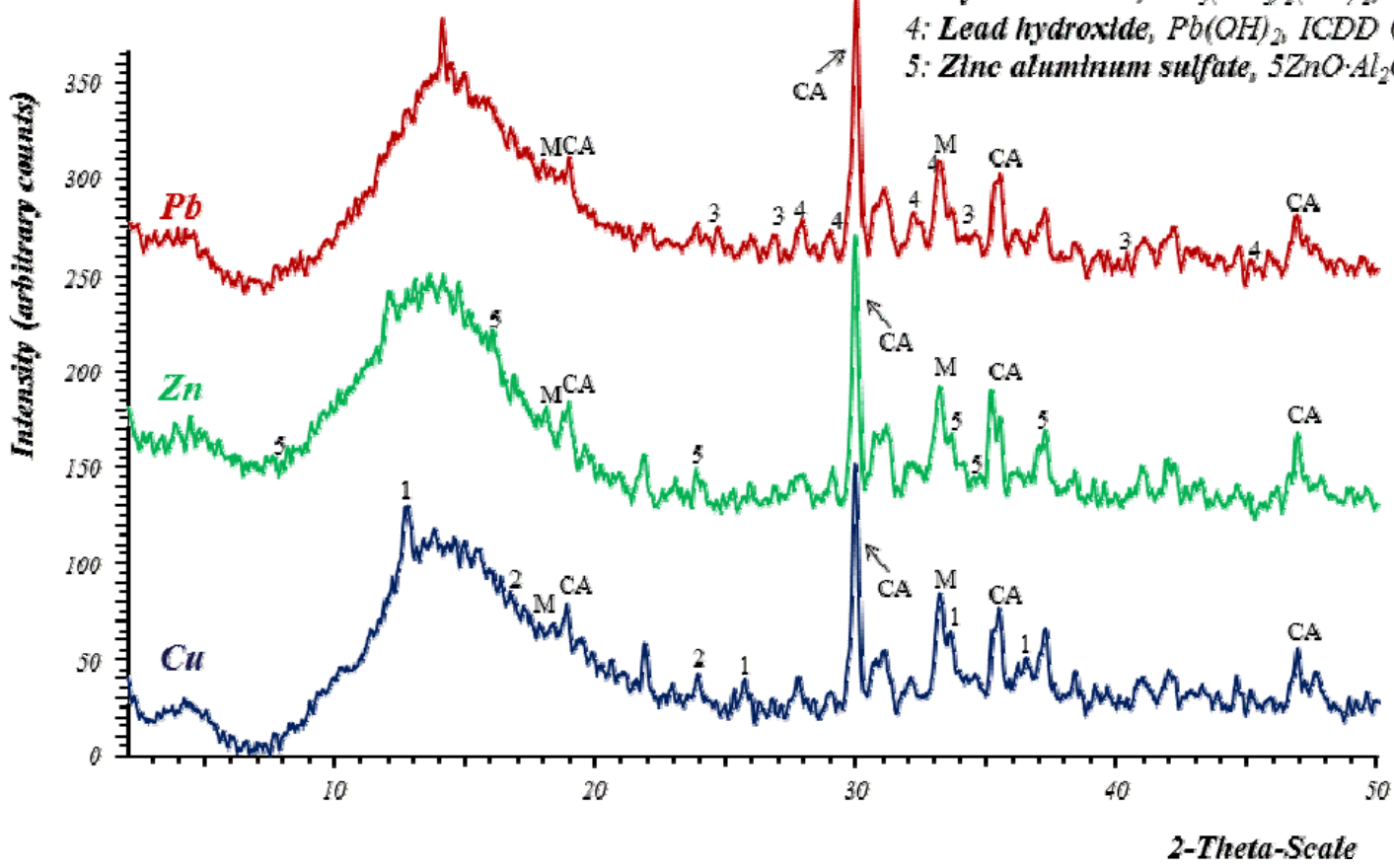

Figure 17. Solid phases XRD analysis after metal sorption studies. 


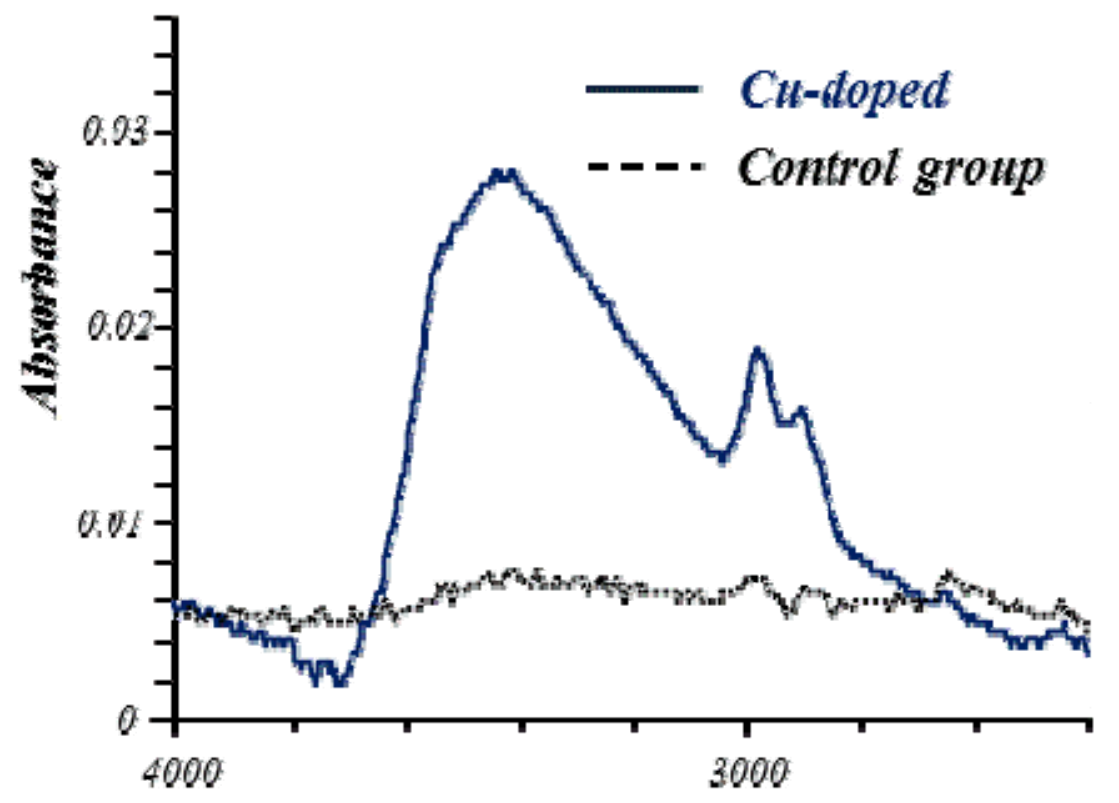

a

Wavenumbers $\left(\mathrm{cm}^{-1}\right)$

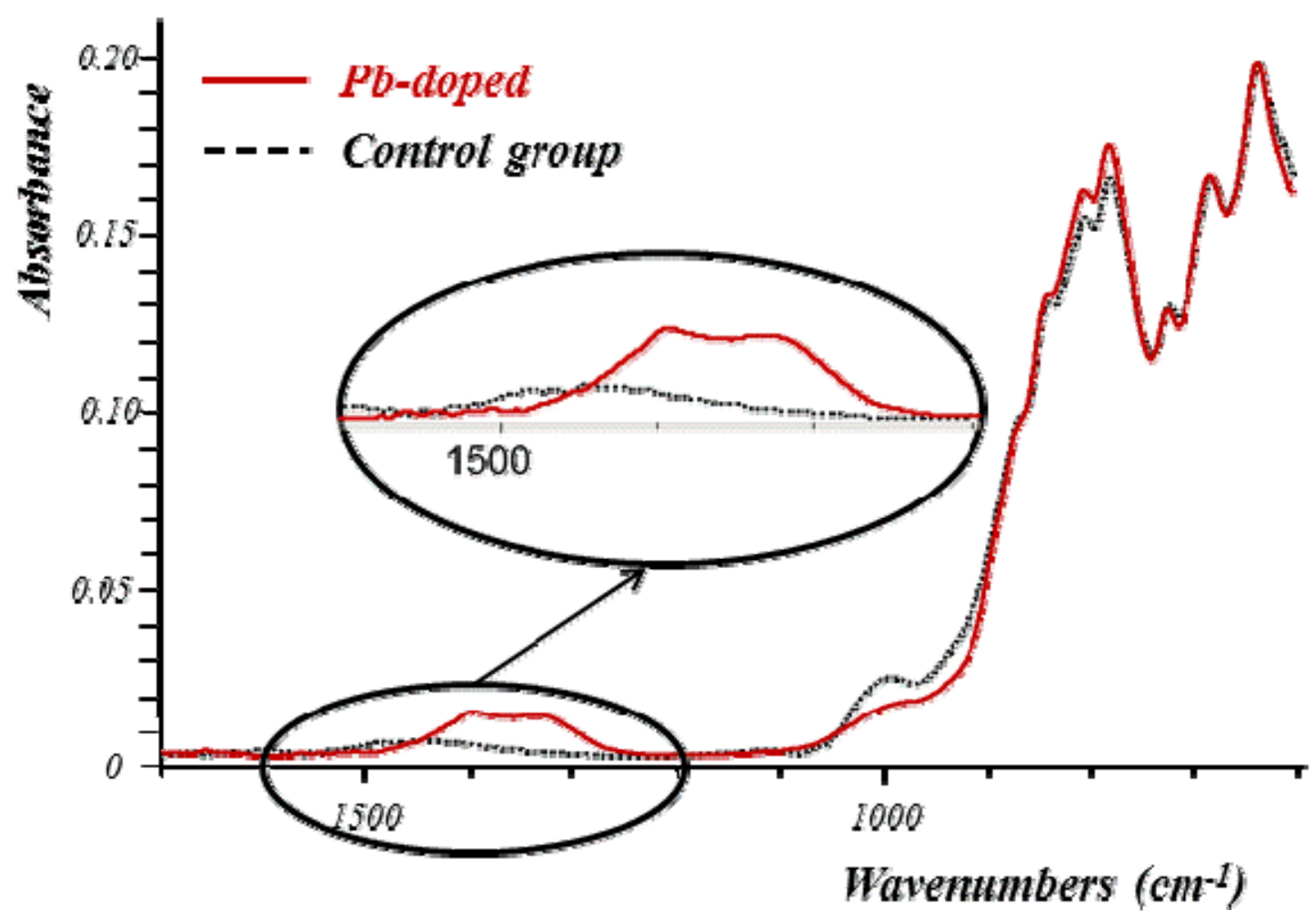

Figure 18. FTIR-ATR spectra of solid phases after metal sorption studies: a) sample after $\mathrm{Cu}$ sorption compared with a free-metal sample; b) sample after $\mathrm{Pb}$ sorption compared with a free-metal sample. 